\title{
Green housing or green gentrification?
}

Armin Yeganeh ${ }^{\mathrm{a}}$, Andrew McCoy ${ }^{\mathrm{a}}$, Philip Agee ${ }^{\mathrm{a}}$, Todd Schenk ${ }^{\mathrm{b}}$, Steve Hankey ${ }^{\mathrm{b}}$

${ }^{\text {a }}$ Myers-Lawson School of Construction, Virginia Tech, USA

${ }^{\mathrm{b}}$ School of Public and International Affairs, Virginia Tech, USA

* Corresponding author: Armin Yeganeh, 1345 Perry St, Blacksburg, VA 24060, USA

Email: yeganeh@vt.edu

Word count: 7,500 words (Excluding the abstract, highlights, figures, tables, captions, references $)+(7)$ tables $+(6)$ figures.

Running title: Green housing or green gentrification? 0(0)

Acknowledgments: The authors wish to acknowledge Viridiant and Richmond Association of Realtors.

Competing financial interest: The authors declare they have no competing financial interests. 


\section{Highlights}

- New, green-certified, single-family houses have transaction price premiums and cause market value spillovers on nearby, non-certified houses.

- Green-certified, single-family units significantly stimulate population growth, housing development, and housing value increases.

- The new construction of green-certified, single-family units accelerates neighborhood change in urban areas, making the areas ripe for gentrification.

- The influence of green certifications on house prices has decreased over time, potentially due to technology diffusion and improvements in conventional residential codes. 


\begin{abstract}
Research on green-certified buildings has often been focused on the benefits of green standards, such as energy efficiency, smart growth, resource conservation, and health protection. Recent studies suggest the adoption of a reductionist sustainability planning language can turn green-certified houses into luxury goods, attracting White, prime-age, college-educated households with some pro-environmental attitudes who replace existing long-term, lower-income residents in core urban areas. While many factors may work together in driving neighborhood change and gentrification in cities, the question this study aims to address is to what extent the supply of green-certified units can affect neighborhood change and gentrification? We use Central Virginia's Multiple Listing Service (MLS) housing market transactions data and the U.S. Census Bureau's socioeconomic data to present the differential effect of new construction of market-rate, green-certified units in a natural experiment using difference-in-differences estimates. We find that neighborhoods that include new, green-certified units have experienced a statistically significant increase in population, supporting new construction and positively affecting house prices. We also detect some negative effects on minorities and minority owners, but these effects have not yet reached statistical significance. This study finds strong evidence of green housing providing the conditions that make areas ripe for gentrification, but more studies should follow up to better measure and generalize this finding.
\end{abstract}

Keywords: affordable housing; environmental justice; equity; green building; housing policy 


\section{Introduction}

The development of green building rating systems in the early 2000s represented the real estate market's response to the need for environmental sustainability and climate change mitigation. Green-certified buildings are planned, designed, constructed, operated, and recycled to increase environmental, health, and productivity performance over that of conventional buildings., and green building rating systems reward relative levels of compliance or performance with certain environmental goals. Past studies have explored co-benefits of green buildings (e.g., energy efficiency, smart growth, resource conservation, and health protection) and numerous cities have incentivized the construction of green buildings, viewing positive effects of green-certified units on property values and tax revenues as an economic benefit and a key to justifying the high cost of green urban redevelopment initiatives [1]. Since these units are attractive to households with growing income and those in the neighborhoods in need cannot afford them, the economic and environmental aspects of redevelopment initiatives can surpass or obscure the equity aspect, resulting in the creation of luxury goods that contribute to the displacement of existing households or increase their cost of living.

The gentrification process involves class-based resettlement of inner cities, a reinvestment in the housing stock, and the displacement of existing residents. Many underlying factors, such as changes in job access, amenity values, house prices, public policies, new technologies, family structure, and demographic composition can be at work in gentrifying neighborhoods [2]. One potential explanation is the role of developers, builders, planners, and policymakers in the supply of urban housing. Recently, social justice researchers have raised concerns over the side effects of homeowners' attraction to new, green-certified homes. Literature has documented the 
presence of contradictory linkages between economic, environmental, and equity goals of development policy and planning in large-scale, smart-growth, mixed-use, and transit-oriented redevelopment initiatives, but few studies might have made progress on the links between gentrification and the new construction of green-certified units to help craft more efficient and equitable housing policies.

This study contributes to the growing body of scholarship on urban sustainability governance by quantifying price premiums, price spillovers, and neighborhood changes connected with the new construction of private-market-led, green-certified, single-family units in Central Virginia. We explore whether the construction of these units can trigger a process of neighborhood change by being unaffordable for the existing community, increasing the value of nearby properties, thereby adding pressures of displacing existing long-term residents. We examine four interrelated hypotheses: 1) Green-certified houses have transaction price premiums; 2) Greencertified houses cause positive spillover effects; 3) Neighborhoods containing green-certified houses experience change and gentrification; 4) The influence of green certifications on house prices has decreased over time. We use Central Virginia Multiple Listing Service (MLS) transactions' pooled cross-sectional data (2005-2019) and the U.S. Census Bureau's Decennial Census (2000) and American Community Survey data (2019) and present the differential effect of the new construction of market-rate, green-certified units in natural experiments using difference-in-differences estimates. The paper opens with a concise review of recent scholarship on environmental gentrification. We then describe the study hypotheses, context, data, and econometric models. In closing, we summarize and discuss the major findings and suggest policy implications and future research avenues. 


\section{Literature review}

\subsection{Environmental gentrification}

Early studies (the 1920-1930s) of neighborhood change had a focus on inner-city neighborhoods' decline and disinvestment and relocation of higher-income residents, but since Ruth Glass applied the term gentrification to describe the displacement of London's working class in the 1960s, the class remake of the central city landscape has attracted notice in the U.S. context [3-5]. As a form of neighborhood change, gentrification is the middle or upper-class colonization of urban property in poor or working-class neighborhoods, accompanied by cultural and demographic shifts and significant displacement of long-time, low-income residents [6]. Since the 2000s, great changes in U.S. central cities have renewed interest in gentrification, leading to the advanced capitalism era's iteration of old discourses about equitable urban development at the convergence of urban redevelopment, ecologically minded initiatives, and environmental justice activism [7]. The terms ecological, environmental, or green gentrification frequently apply to the process in which "pro-environment" policies, programs, or practices aimed at responding to the demand for livable urban environments and/or reduced suburbanization exclude, displace, and discriminate against existing, low-socioeconomic status residents [8]. A growing number of studies describe investments in large-scale environmental initiatives, e.g., green spaces, smart growth, mixed-use densification, and transit-oriented development in brownfields and core urban areas - where the difference between the actual and potential ground rent is high - have replaced low-rent units occupied by low-socioeconomic status residents with high-end real estate for higher-income, often white in-migrants, who tend to inhabit, rebuild, upgrade, or rent out existing units at a higher rent [9-12]. The environmental 
justice scholarship attributes environmental gentrification to post-industrial cities' selective adoption of environmental sustainability as a redevelopment framework.

Sustainability thinking has long encouraged integrated, interdisciplinary approaches and policies that holistically address multiple contemporary problems and achieve a balanced integration of economic, environmental, and equity goals in traditionally siloed policy sectors, such as housing, transport, and agriculture [13-15]. In this mindset, substantive policy goals in broad and diverse sectors like energy, environment, and climate change, cannot be realized until incorporated into other sectors [16-18]. Nonetheless, conflicts arise when achieving the goals of one pillar of sustainability, i.e., economy, environment, and society, is incompatible with achieving the goals of another pillar (Figure 1). Environmental gentrification is an environmentequity conflict of sustainability, which is the economic conundrum of providing sustainable conditions for the natural environment and, simultaneously, a subsistence existence for lowsocioeconomic status populations [19]. The environmental justice scholarship - through the lens of distributive, procedural, or interactional justice - has highlighted disparities in environmental amenities (e.g., clean air and water, landscape, green transport infrastructure, public parks, beaches) that increasingly divide today's cities, informing activists to improve neighborhood conditions for low-socioeconomic-status groups by removing environmental burdens like air and water pollution, toxic and hazardous facilities, vehicle traffic, landfill sites, flood risk [20,21]. Researchers have developed a wide array of approaches, strategies, and instruments that facilitate the integration of policy goals into development planning and address inherent conflicts involved in reaching sustainable development when existing environmental burdens in cities are reinvested and transformed into environmental amenities [22-24]. 


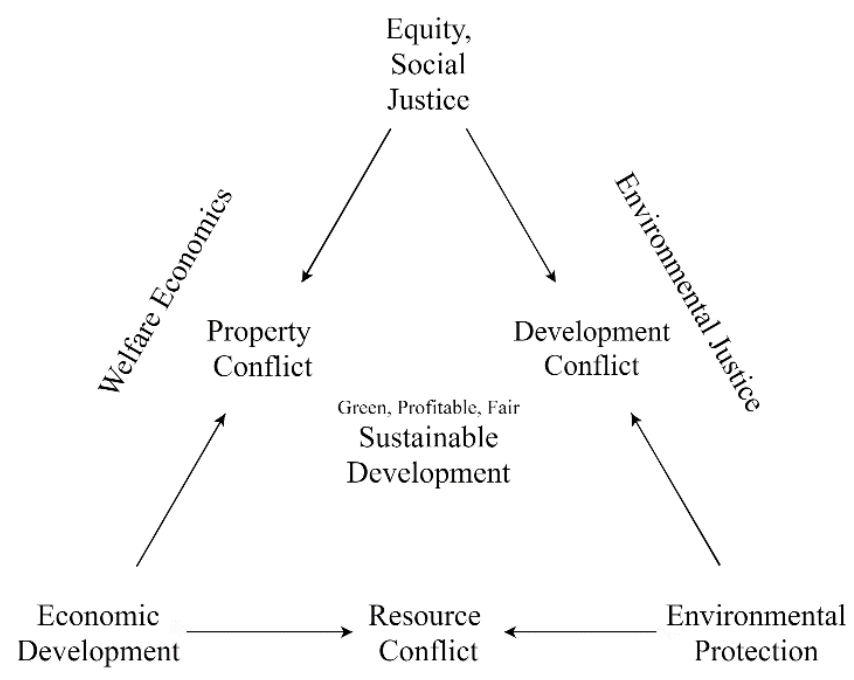

Environmental Economics

Figure 1 Conflicting planning goals triangle [19]

Selective adoption of environmental sustainability would reduce the net benefit for the city. When a neighborhood is subject to gentrification, the cost-burdened, relocated, or displaced residents incur economic costs (e.g., job loss, falling wages, moving costs, housing costs, and transportation costs), social costs (e.g., crime increases, loss of community support, disruptions in the network of acquaintances), and health and well-being costs (e.g., damages to physical and mental health, disruptions in kids schooling), thus, requiring support from the host neighborhood and creating large negative externalities leading to welfare loss in the city [25]. Figure 2 illustrates welfare gains from incentivizing actions to protect existing residents. In the freemarket economy, residents underestimate the true social value of community protection actions. Introducing an incentive would increase the number of available resources for action (Q1) toward a socially optimal level $(\mathrm{Q} 2)$, where the marginal cost of action to the community (MPC/MSC) is equal to the marginal social benefit of action (MSB). The upward shift in the 
marginal private benefit (MPB) curve creates the triangular grey area, representing the quantity of positive externality known as welfare gain from an action [26].

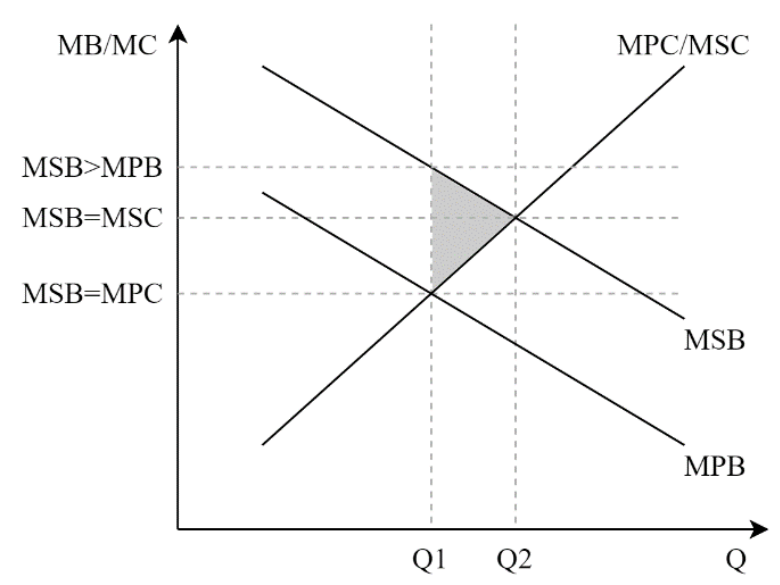

Figure 2. Incentivizing actions against displacement leads to welfare gain.

With substantial reductions to spending on public projects, private funders are key players in environmental gentrification. Researchers contend that environmental gentrification is not always an unintended consequence of regulatory processes and procedures. Rather, city governments, private funders, real estate developers, and political, economic, and cultural elites work together in coalitions that exploit underserved neighborhoods with low property values to deliberately establish "neighborhood revitalization projects" that attract higher-income, primeage, environmentally-minded professionals [27]. This collaboration in neoliberal urbanism satisfies the needs of public agencies and private developers through increased property tax revenues and substantial price premiums at the cost of social equity. The influx of high-income residents after such projects can disintegrate environmental and affordable housing goals, remove connections between public and non-for-profit actors, destroy local culture, and increase housing costs by changing the class composition of the neighborhood. 


\subsection{Could green buildings incite gentrification?}

Fueled with an ever-increasing interest in pro-environment real estate, numerous green building rating systems have emerged since the 2000s, which reward relative levels of compliance with certain construction requirements. In the US context, an analysis of LEED and Energy Star-certified properties over the first decade of implementation suggests improvements in the rate of adoption, the share of private developers, the share of buildings certified at higher certification levels, and certification standards [28]. Some rating systems like Energy Star for Homes have a single focus area; some like LEED cover multiple components (e.g., energy efficiency, smart growth, resource conservation, and health protection); advanced rating systems like the Living Building Challenge require expensive, cutting edge, innovative practices far beyond standard building codes and may include a community consideration. The literature explains the growth in the proportion of green-certified properties in cities by the economic, environmental, political, societal, and technological composition of cities [29,30].

Since green-certified houses incur an extra upfront cost of compliance with green building certification requirements, builders may charge over a $10 \%$ price premium for conventional green building certifications [31-33]. A $10 \%$ premium was an equivalent of, at least, $\$ 40,000$ in the median new house price in the first half of the year 2021 in the U.S., where the federal minimum wage for blue-collar jobs remained at only $\$ 7.25 / \mathrm{hr}$ for the years to come. In this situation, real estate investors' confidence in the ability to recover upfront costs through sales or rent premiums would significantly increase by favorable market conditions (e.g., high property values, high energy prices, low vacancy rates, and low days on market), supportive political regulations and incentives, and the presence of higher-income, college-educated professionals whose environmental desires would align with green-certified units [34]. 
Private-sector-led urban intensification projects involving the construction of green-certified houses have been criticized for a lack of deep engagement with social justice and ecological principles. The production of green-certified units in underserved urban areas where the difference between the actual and potential ground rent is high helps developers recoup cost premiums by attracting high-income households who find value in new urban design trends that enhance walking or biking, the economies of compact, mixed-use neighborhoods, and new technologies that help reduce vehicle miles driven. New households may observe savings from energy efficiency, but, together, the level of consumption of high-income residents, the rebound effect, and the high embodied energy of these projects would lead to significant carbon emissions [35]. Displaced households who tend to have very limited access to modern energy and technology, causing very low carbon emissions, would likely incur disproportionate costs. Some scholars argue that the development of LEED has been primarily motivated by economic considerations, and, to smaller degrees, environmental considerations, with a disregard for social processes that shape urban environments. For instance, LEED rewards occupant health promotion largely aimed at improving worker productivity in occupational settings and accredits environmental impact reduction without mandating a specific scientific benchmark.

Literature conceptualizes recent forms of local economy-environment relations through the notion of "urban sustainability fix," or the selective incorporation of ecological goals in urban governance to safeguard post-industrial urban growth in response to the global ecological crisis and the rise of popular environmentalism [36]. In this approach, the politics of urban development support environmental and social goals only so long as economic goals are not diminished. One of such instances described in the literature is the high-density, mixed-use redevelopment of public lands on Toronto's waterfront, where a process of policy-led 
gentrification supports middle-to-high-income-oriented property development at the expense of housing affordability [37]. Toronto's financial and educational incentives for LEED-certified structures drive the development of the "revitalization project" by large, globally financed, private development corporations that have the capital to absorb the upfront costs of developing, publicizing, and marketing Gold-level LEED-certified properties. Another example is Portland's investment in an urban growth boundary, transit-oriented development, and infill construction, which has contributed to the City reputation for commitment to livability and sustainability by transforming vacant lots into stylish, LEED-certified condos and retail hubs, but, at the same time, has multiplied housing costs and displaced long-term, low-socioeconomic status residents [38].

\subsection{Measuring gentrification}

Markers of gentrification often include an influx of new residents of higher socioeconomic status, increases in house prices and rents, improvements in amenities, and changes in physical, cultural, and demographic characteristics [2]. Therefore, researchers have used many indicators, operationalization methods, analysis units, and degrees of change to study gentrification. Since neighborhoods (i.e., physical aspects) and communities (i.e., societal aspects) may both change, physical changes may be tracked and compared using a composite index or multiple indicators of physical, occupancy, and financial characteristics of the building stock (e.g., assessed values, investments, ownership rates, prices, rents, renovated buildings, taxes), while societal changes are tracked and compared with a composite index or multiple socioeconomic indicators of inhabitants and businesses (e.g., the flow of White, prime-age, college-educated, middle- or high-income households) between temporal and geographical units of analysis [6,10]. 
To identify the severity of gentrification, some researchers have operationalized neighborhoods using Census administrative units of analysis (e.g., tracts and block groups) due to both convenience and availability of data, although these units do not necessarily delineate a homogenous area that has a distinct identity [25]. Census tracts generally have a population size between 1,200 and 8,000 people, and block groups are statistical divisions of census tracts, generally defined to contain between 600 and 3,000 people. For instance, Freeman (2005) uses Census data to track tract-level changes in household income, housing stock, urbanization, house prices, and educational attainment relative to the corresponding metro-level over a predefined period and designates tracts as either gentrifying or stable [39]. Landis (2016) tracks changes in tract-level median household income deciles within a metropolitan area and categorizes tracts as gentrifying, declining, or stable, depending on the severity of changes often within a one-to-twodecade timeframe [6]. Some researchers have developed multiple categories to capture a more nuanced understanding of gentrification stages using several neighborhood and community indicators from multiple datasets, and some others have used visual data from Google Street View imagery to characterize physical changes in gentrifying neighborhoods [40,41]. Comparative studies suggest that the choice of the research method has a large impact on neighborhood categorization but the results share similarities across the studies $[42,43]$.

A growing number of studies have quantified the gentrification impacts of pro-environmental redevelopment projects. Immergluck \& Balan [44] examines the effect of the Atlanta Beltline - a transit-oriented redevelopment of historic railroad corridors, providing a network of public parks and multi-use trails - on value and tax appreciation of units located within one-half mile of the project over five years. The study finds significant evidence on the creation of exclusionary housing patterns near the project, where economically advantaged households enjoy new 
subsidized amenities, whereas lower-income households are forced to live in less attractive neighborhoods. Dong [10] explores potential gentrification effects of rail transit development in suburban Portland, Oregon, employing tract-level data on the demographic composition, housing characteristics, and location in a longitudinal quasi-experimental design. The study uses propensity score matching to designate treatment and control neighborhoods and applies several statistical t-tests to identify changes at multiple observation points and timeframes, but the study does not indicate significant transit-induced gentrification.

This review suggests there are certain methodological challenges in quantifying the causes and effects of gentrification. First, selected geographical and temporal analysis units, data, variables, and operationalization methods can have a large impact on the results. Second, case studies are highly context-specific, thus, increasing the probability of biased comparisons. Some neighborhoods are already very different from others before the introduction of a new project and "apples-to-apples" comparisons are difficult to achieve. Third, relying on administrative geographical units and aggregated Census data, for instance, to measure housing affordability without differentiating households of different income levels, may mask underlying nuances and reduce accuracy. Past research has primarily focused on the adversities of large infrastructural public-private partnership projects for vulnerable residents. This study has a focus on gray infrastructure gentrification driven by urban climate and sustainability politics, private developers' interest in market-rate, green-certified units, and middle- and higher-income residents' desire to live in energy-efficient houses in mixed-use, dense, walkable, bikeable neighborhoods. The analysis examines hypotheses on price premiums, price effects, and neighborhood and community effects of green-certified houses, which would inform equityminded housing planners, organizations, rating systems, and policymakers. 


\section{Methodology}

\subsection{Research hypotheses}

Hypothesis (1): Green-certified houses have transaction price premiums. We can expect that green price premiums reflect, at least, the upfront construction cost premium and developer margins to achieve the green certification in a non-competitive market context, and, at most, the homebuyers' willingness to pay for perceived operational benefits, e.g., savings from energy and water-efficiency, productivity gains from indoor environmental quality, and a positive green image in a competitive context. Identical certified units in comparable neighborhoods may signal different price premiums if environmental attitudes vary across communities.

Hypothesis (2): Green-certified houses cause positive market value spillover effects. When single-family units are demolished, the positive price impacts on existing, nearby units can be higher if the demolished units are replaced with a green-certified unit, rather than an identical non-certified unit. Environmentally savvy homebuyers willing to spend extra to live in a brand new, green-certified unit tend to have higher incomes. Analyzing spillover effects may require an additional degree of control over confounding variables, e.g., when a unit is replaced with several green-certified units, the resulting increase in neighborhood density, traffic, and noise may hurt existing property values.

Hypothesis (3): Neighborhoods accommodating green-certified houses experience change and gentrification. The main question here is, if green-certified units raise property values and tax revenues, to what extent are these units connected with neighborhood change and gentrification? The supply of green-certified units in neighborhoods where the difference between the actual and potential ground rent is high can help developers recoup cost premiums, 
and homebuyers may speculate that lifecycle homeownership cost reductions justify the price premium. We expect the siting of green-certified units to cause or be associated with neighborhood change and even gentrification if there is no policy in place to protect existing, low-income residents from displacement.

\section{Hypothesis (4): The influence of green certifications on house prices has decreased over}

time. Employing historical market data to measure willingness to pay assumes that future market behavior can be predicted using revealed preferences in the past. However, as conventional building codes and construction methods improve, green building standards may not be needed as they once were to prove the quality and efficiency of units. Anecdotal evidence suggests that as builders gain experience in green-certified construction, they tend to include green features in developments without pursuing the certification itself to reduce the total cost of development. However, in parallel to advances in conventional construction codes, materials, methods, and professional workforce, green rating systems may evolve and improve net income returns by addressing economic, geographical, and functional needs of developers and helping consumers maintain a positive green image by the time debates on global environmental issues persist.

\subsection{Study context and datasets}

The study area is a Richmond Metropolitan Statistical Area (MSA) submarket, including the counties of Chesterfield, Goochland, Hanover, Henrico, New Kent, and Powhatan and the cities of Colonial Heights, Petersburg, and Richmond. We obtained Central Virginia Multiple Listing Service (MLS) transactions pooled cross-sectional data from 01\01\2005 to $01 \backslash 01 \backslash 2020$, cleaned the dataset, and geocoded the addresses in ESRI's ArcMap using Virginia Geographic Information Network (VGIN). We obtained the list of green-certified, single-family units from 
Viridiant and modified the original MLS dataset for accuracy. The EarthCraft green building rating system was established in 1999 and extended to Virginia in 2006 as EarthCraft VA, called Viridiant as of 2018, one of the largest regional green building programs in the U.S. To obtain a matched sample based on geography, the sample includes all EarthCraft-certified (hereinafter certified) single-family units plus all non-certified single-family units in a one-mile radius distance from the certified units. The sample has over 50,000 transactions, representing nearly 550,000 units in Richmond MSA with a $1 \%$ error margin and a 99\% confidence interval. A priori power analysis suggests our models detect small effect sizes (f2) with the statistical power of 0.99 at the alpha level of 0.01 [45]. We obtained the Decennial Census 2000 data and the ACS 2019 5-year estimate data to quantify socioeconomic changes before (the year 2000) and after (years 2014-2018) the construction of certified units. The 5-year estimates have larger samples and smaller margins of error than 1-year estimates but are less current. We mapped the tractlevel and block group-level datasets in ArcMap and joined the year 2000 data to the year 2019 shapefiles to ensure changes in titles and delineations of tracts and block groups in the last two decades would not impact the analysis (National Historical Geographic Information System (https://nhgis.org/) has time-series products that preserve the same Census geographies overtime to remove this type of issue.)

\subsection{Statistical analysis}

Hypothesis (1): Formulated by Rosen [46], the theory of hedonic prices hypothesizes that goods are valued based on their utility-bearing attributes. Numerous housing studies have used multivariate regression analysis to infer unobservable values of structure, lot, and location attributes based on the theory of hedonic prices. In classic hedonic price functions, the observed 
market price of housing expenditure equals the sum of the marginal price of independent housing attributes [47]. Typically, the function is specified as Equation (1), where $\ln v_{i}$ is the natural logarithm of - the total or per areal unit - unit transaction price, which is the agreed transaction price of the property between the buyer and the seller excluding legal, agency, and other professional fees; $S_{i}, L_{i}$, and $N_{i}$ are vectors of the structure, lot, and neighborhood characteristics; $\alpha, \beta$, and $\gamma$ are vectors of unknown coefficients, and $\varepsilon_{i}$ is a vector of random error terms in ordinary least squares regression (OLS). To test the first hypothesis, we rewrite Equation (1) as Equation (2) where $G_{i}$ is a binary variable, indicating whether unit $i$ is certified; $Y_{m}$ and $M_{n}$ denote the fixed effects of the year and month of transaction; $C$ is the constant term; and $\eta, \delta$, and $\theta$ are coefficients. Having a sample of all non-certified, single-family units in a one-mile radius distance from the certified units can reduce the need for one-to-one matching, and adding the neighborhood characteristics of density, income, and race, can reduce the risk of a selection bias, i.e., positive spatial externalities causing the green premium.

$$
\begin{aligned}
& \ln v_{i}=S_{i} \alpha+L_{i} \beta+N_{i} \gamma+\varepsilon_{i} \\
& \ln v_{i}=G_{i} \eta+\sum_{j=1}^{n_{S}} S_{j} \alpha_{j}+\sum_{k=1}^{n_{L}} L_{k} \beta_{k}+\sum_{l=1}^{n_{N}} N_{l} \gamma_{l}+\sum_{m=1}^{n_{Y}} Y_{m} \delta_{m}+\sum_{n=1}^{n_{M}} M_{n} \theta_{n}+C+\varepsilon_{i} \quad \text { Equation } 2 \\
& \ln v_{i}=A_{i} \kappa+W_{i} \lambda+D_{i} \mu+S_{i} \alpha+L_{i} \beta+N_{i} \gamma+\varepsilon_{i}
\end{aligned}
$$

Hypothesis (2): To test this hypothesis, we add new attributes to the equation so that the resulting model captures two types of spatial externalities: fixed neighborhood effects due to shared neighborhood characteristics and spillover effects due to adjacency to immediate, 
certified units. The basic hedonic regression has been used to estimate spillover effects, assuming an accurately specified hedonic regression model that includes all confounding covariates can reasonably capture causal effects [48]. However, it is often not possible to identify and include all confounders measured appropriately. Nonetheless, to rule out the probability of a selection bias (i.e., the possibility that developers strategically locate certified units in "strong areas", where the prices of existing properties are consistently high) we employ a difference-indifference estimator that measures differences in the prices of nearby properties relative to properties in the control group before and after the construction of a certified unit [49]. This natural experiment is of course still an observational method using Census data, not a randomized controlled trial, which is not possible here, but approaches we use, e.g., propensity matching, spatial matching, and difference-in-differences try to approximate a more robust design. In Equation (3), $A_{i}$ is a binary variable that indicates whether unit $i$ is sold one or more years after a certified unit is built; $W_{i}$ is a binary variable that indicates whether unit $i$ is in a walkable distance (i.e., in a quarter mile radius) to a certified unit; and $D_{i}$ is a binary variable that captures both the spatial and time dimensions, indicating whether unit $i$ is both located in walking distance to a certified unit and sold one or more years after a certified unit is built. Table 1 summarizes the expected values of $\ln v_{i}$ in Equation (3). Coefficient $\lambda$ reflects the baseline differences in the transaction price of units located inside and outside of a walkable distance to a certified unit. Coefficient $\mu$ is the difference in differences estimate and reflects the true spillover effect of building a certified unit. 
Table 1 Expected values of $\ln v_{i}$ in Equation (3)

\begin{tabular}{llll}
\hline Estimate & Pre-build & Post-build & Difference \\
\hline & & & $\kappa+\mu$ \\
In walkable distance & $\lambda+S+L+N$ & $\kappa+\lambda+\mu+S+L+N$ & $\kappa+\mu$ \\
Out of the walkable distance & $S+L+N$ & $\kappa+S+L+N$ & $\kappa$ \\
Difference & $\lambda$ & $\lambda+\mu$ & $\mu$ \\
& & & \\
\hline
\end{tabular}

Hypothesis (3): We test the third hypothesis in terms of both the association between certified house accessibility and transaction price appreciation over time and the connection between the presence of certified houses and neighborhood socioeconomic change. To represent certified house accessibility, we introduce an ordinal variable composed of the year-specific quintiles of the mean geodesic distance based on the Vincenty [50] formula between each non-certified unit and all the existing certified units (Model-3). We then add interactions of the transaction year and the ordinal measure of accessibility (Model-4) to indicate how much cumulative appreciation over time is associated with certified house accessibility [44]. To examine the connection to neighborhood socioeconomic change, we identify Census tracts and block groups that are sites of certified houses and compare multiple indicators of sociodemographic changes using difference-in-differences analyses, presenting the differential effect of the new construction of market-rate, certified units at the two geographical scales in a natural experiment.

Hypothesis (4): We use Equation (2) in a repeated pooled cross-sectional design for houses sold in the three intervals of 2005-2009, 2010-2014, 2015-2019 (Model-5).

All statistical analyses are performed in Stata 14.0. To prevent multicollinearity, we examine Variance Inflation Factors (VIFs) and avoid the use of highly correlated variables in regression models based on the assumption that the presence of zero-order Pearson coefficients larger than 0.80 denotes multicollinearity [51]. To ensure other underlying OLS regression assumptions are not violated, we inspect standardized normal probability plots of residuals and residuals-versus- 
fitted-values graphs and use robust standard errors. The socioeconomic estimates are reliable at both Census tract and block group levels when assessed against the coefficient of variation.

\section{Results}

\subsection{Do green-certified houses have transaction price premiums?}

Table 2 reports descriptive statistics of the sample variables. The dependent variable in all the hedonic price models is the natural logarithm of the transaction price. The average sample singlefamily unit price in the year 2019 is $\$ 331,844.20$ (S.D. 167,563.60), having a floor area of 2,322.87 SF (S.D. 1,067.51). The sample includes a total of 516 certified transactions from $01 \backslash 01 \backslash 2005$ to $01 \backslash 01 \backslash 2020$, the market share of which reached the highest level in the year 2012 when $11.28 \%$ of all the new sales were certified and declined to the lowest level in 2019 when $4.85 \%$ of all the new sales were certified. Corresponding to the first three hypotheses, Table 3 presents three multivariate regression models, including a set of fixed effects that control for the city, year, and month of sales. Overall, the models perform well as most equation coefficients are significant at the $1 \%$ level, and the regressions explain over $86 \%$ of price variations. 
Table 2 Hedonic price model variable definitions and descriptive statistics based on a final sample size of 57,673.

\begin{tabular}{|c|c|c|c|c|c|}
\hline Variable & Operationalization & Mean & Std. Dev. & Min* & $\operatorname{Max}^{*}$ \\
\hline \multicolumn{6}{|l|}{ Dependent variable } \\
\hline Sales Price & Natural logarithm of total transaction price & 12.450 & 0.585 & 10.222 & 14.602 \\
\hline \multicolumn{6}{|l|}{ Main independent variables } \\
\hline EarthCraft & If unit is EarthCraft (EC) certified ( $1=$ yes) & 0.009 & 0.094 & & \\
\hline Post EC & If unit is sold after an EC unit was built ( $1=$ yes $)$ & 0.915 & 0.279 & & \\
\hline Near EC & If unit is within a quarter mile of an EC unit ( $1=$ yes) & 0.233 & 0.423 & & \\
\hline Post EC * Near EC & If unit is sited near to and sold after an EC unit ( $1=$ yes) & 0.144 & 0.352 & & \\
\hline Q2 Distance to EC & If mean unit distance to existing EC units is in $2^{\text {nd }}$ quintile & 0.2000 & 0.4000 & & \\
\hline Q3 Distance to EC & If mean unit distance to existing EC units is in $3^{\text {rd }}$ quintile & 0.2000 & 0.4000 & & \\
\hline Q4 Distance to EC & If mean unit distance to existing EC units is in $4^{\text {th }}$ quintile & 0.2000 & 0.4000 & & \\
\hline Q5 Distance to EC & If mean unit distance to existing $\mathrm{EC}$ units is in $5^{\text {th }}$ quintile & 0.2000 & 0.4000 & & \\
\hline \multicolumn{6}{|l|}{ Control variables } \\
\hline \multicolumn{6}{|l|}{ Structure } \\
\hline Area & Natural $\log$ of the interior area in square feet & 7.644 & 0.448 & 5.951 & 9.463 \\
\hline Baths $(\mathrm{F})$ & Total number of full bathrooms & 2.150 & 0.868 & 0 & 8 \\
\hline Baths $(\mathrm{H})$ & Total number of half bathrooms & 0.651 & 0.529 & 0 & 5 \\
\hline Year built & Year of construction & 1978.984 & 31.541 & 1900 & 2019 \\
\hline Assessed & If unit price is validated by assessor $(1=$ yes $)$ & 0.864 & 0.343 & & \\
\hline Brickwork & If unit facade has brickwork ( $1=$ yes $)$ & 0.354 & 0.478 & & \\
\hline Detached & If unit is detached ( 1 = yes) & 0.957 & 0.203 & & \\
\hline New construction & If unit is new at sales time ( $1=$ yes $)$ & 0.187 & 0.390 & & \\
\hline Pool & If unit has a pool ( 1 = yes $)$ & 0.093 & 0.290 & & \\
\hline \multicolumn{6}{|l|}{ Location } \\
\hline Lot area (2) & $0.1 \mathrm{ac}<=$ Total lot area $<0.2 \mathrm{ac}(1=$ yes $)$ & 0.119 & 0.323 & & \\
\hline Lot area (3) & $0.2 \mathrm{ac}<=$ Total lot area $<0.4 \mathrm{ac}(1=$ yes $)$ & 0.281 & 0.450 & & \\
\hline Lot area (4) & $0.4 \mathrm{ac}<=$ Total lot area $(1=$ yes $)$ & 0.240 & 0.427 & & \\
\hline Distance to Airport & Natural log of distance to the airport in miles & 14.830 & 6.720 & 2.772 & 73.926 \\
\hline Distance to County & Natural log of distance to County in miles & 6.372 & 5.813 & 0.185 & 78.327 \\
\hline Cul-De-Sac & If lot is in cul-de-sac $(1=$ yes $)$ & 0.120 & 0.325 & & \\
\hline $\mathrm{HOA}$ & If homeowner association is present $(1=$ yes $)$ & 0.407 & 0.491 & & \\
\hline \multicolumn{6}{|l|}{ Neighborhood** } \\
\hline Density & Housing units per square mile tract area & 1176.543 & 1506.496 & 16.655 & 12322.920 \\
\hline Income & Median household income in 1000 USD in 2010 & 74695.010 & 30615.690 & 11458.000 & 221767.000 \\
\hline Race & Percent White households & 70.620 & 26.893 & 2.300 & 100.000 \\
\hline Sales city fixed effects & A set of binary variables representing sales city & & & & \\
\hline Sales year fixed effects & A set of binary variables representing sales year & 2012.257 & 4.625 & 2005 & 2019 \\
\hline Sales month fixed effects & A set of binary variables representing sales month & 6.676 & 3.142 & 1 & 12 \\
\hline
\end{tabular}


Table 3 OLS regression analyses of house prices based on the theory of the hedonic prices

\begin{tabular}{|c|c|c|c|c|c|c|}
\hline & Model 1 & & Model 2 & & Model 3 & \\
\hline & Coef. & R. Std. Err. & Coef. & R.Std. Err. & Coef. & R.Std. Err. \\
\hline EarthCraft $(n=516)$ & $0.0494 * * *$ & 0.0091 & - & - & - & - \\
\hline Post EC build & - & - & $0.2016^{* * *}$ & 0.0046 & - & - \\
\hline Near EC & - & - & $-0.0225^{* * *}$ & 0.0036 & - & - \\
\hline Post EC * Near to EC & - & - & $0.0418 * * *$ & 0.0043 & - & - \\
\hline Q2 EC Accessibility & - & - & - & - & $-0.0804 * * *$ & 0.0044 \\
\hline Q3 EC Accessibility & - & - & - & - & $-0.0793 * * *$ & 0.0045 \\
\hline Q4 EC Accessibility & - & - & - & - & $-0.1033 * * *$ & 0.0047 \\
\hline Q5 EC Accessibility & - & - & - & - & $-0.1152 * * *$ & 0.0051 \\
\hline \multicolumn{7}{|l|}{ Structure } \\
\hline Area & $0.7104 * * *$ & 0.0048 & $0.7088^{* * *}$ & 0.0048 & $0.7107 * * *$ & 0.0050 \\
\hline Baths (F) & $0.0757 * * *$ & 0.0019 & $0.0759 * * *$ & 0.0019 & $0.0745^{* * *}$ & 0.0020 \\
\hline Baths $(\mathrm{H})$ & $0.0531 * * *$ & 0.0023 & $0.0537 * * *$ & 0.0023 & $0.0513 * * *$ & 0.0024 \\
\hline Year built & $0.0006^{* * * *}$ & 0.0001 & $0.0006^{* * *}$ & 0.0001 & $0.0007 * * *$ & 0.0001 \\
\hline Assessed & $0.0048^{*}$ & 0.0027 & 0.0037 & 0.0028 & $0.0093 * * *$ & 0.0031 \\
\hline Brickwork & $0.0391 * * *$ & 0.0020 & $0.0403 * * *$ & 0.0020 & $0.0340 * * *$ & 0.0022 \\
\hline Detached & $-0.0249 * * *$ & 0.0057 & $-0.0250 * * *$ & 0.0057 & $-0.0276 * * *$ & 0.0061 \\
\hline New construction & $0.1381 * * *$ & 0.0026 & $0.1394 * * *$ & 0.0027 & $0.1435^{* * *}$ & 0.0028 \\
\hline Pool & 0.0037 & 0.0028 & 0.0029 & 0.0028 & $0.0055^{*}$ & 0.0028 \\
\hline \multicolumn{7}{|l|}{ Location } \\
\hline Lot area (2) & $0.0107 * * *$ & 0.0036 & $0.0114 * * *$ & 0.0037 & $0.0073 * * *$ & 0.0038 \\
\hline Lot area (3) & $-0.0162 * * *$ & 0.0023 & $-0.0154 * * *$ & 0.0023 & $-0.0167 * * *$ & 0.0024 \\
\hline Lot area (4) & $-0.0182 * * *$ & 0.0026 & $-0.0176 * * *$ & 0.0026 & $-0.0205 * * *$ & 0.0027 \\
\hline Distance to Airport & $0.0011 * * *$ & 0.0003 & $0.0010 * * *$ & 0.0003 & $0.0033^{* * * *}$ & 0.0003 \\
\hline Distance to County & $-0.0006 * * *$ & 0.0003 & $-0.0006^{* * *}$ & 0.0002 & $-0.0012 * * *$ & 0.0003 \\
\hline Cul-De-Sac & $0.0156^{* * *}$ & 0.0022 & $0.0158 * * *$ & 0.0022 & $0.0147 * * *$ & 0.0023 \\
\hline $\mathrm{HOA}$ & $0.0770 * * *$ & 0.0025 & $0.0764 * * *$ & 0.0025 & $0.0832 * * *$ & 0.0026 \\
\hline \multicolumn{7}{|l|}{ Neighborhood } \\
\hline Density & $3.9500 \mathrm{E}-05^{* * *}$ & $1.0300 \mathrm{E}-06$ & $3.9200 \mathrm{E}-05 * * *$ & $1.0400 \mathrm{E}-06$ & $3.8200 \mathrm{E}-05^{* * *}$ & $1.1000 \mathrm{E}-06$ \\
\hline Income & $2.0200 \mathrm{E}-06^{* * * *}$ & $5.3700 \mathrm{E}-08$ & $2.0200 \mathrm{E}-06 * * *$ & $5.4400 \mathrm{E}-08$ & $1.9800 \mathrm{E}-06 * * *$ & $5.6800 \mathrm{E}-08$ \\
\hline Race & $6.4925 \mathrm{E}-03 * * *$ & $6.7700 \mathrm{E}-05$ & $6.5110 \mathrm{E}-03 * * *$ & $6.8200 \mathrm{E}-05$ & $6.0097 \mathrm{E}-03 * * *$ & 7.6300E-05 \\
\hline Sales city fixed effects & Included & & & & Included & \\
\hline Sales year fixed effects & Included & & & & Included & \\
\hline Sales month fixed effects & Included & & & & Included & \\
\hline Constant & $4.7341^{* * *}$ & 0.1340 & $4.7460^{* * *}$ & 0.1352 & $4.6251^{* * * * *}$ & 0.1474 \\
\hline Observations & 57,673 & & 57,157 & & 52,373 & \\
\hline Adj R-squared & 0.8638 & & 0.8640 & & 0.8621 & \\
\hline $\begin{array}{l}\text { Post EC build* Near to EC Conf. Interval } \\
* \text { Represents significant at } 10 \% \\
* * \text { Represents significant at } 5 \% \\
* * * \text { Represents significant at } 1 \%\end{array}$ & & & 0.0333 & 0.0503 & & \\
\hline
\end{tabular}


Most of the control variables have the expected signs and the models suggest that prices decline as distance to the central business district increases. On the other hand, units located near the airport are sold at a discount, suggesting the presence of countervailing, negative externalities from noise and congestion. To interpret the percentage change in transaction price in these semi-log models, where the dependent variable has been log-transformed but the predictors have not, we exponentiate the coefficient of the independent variable, subtract one from the result, and multiply it by 100. In Model 1, the positive and statistically significant coefficient for EarthCraft implies that, all the variables held constant at the average, certified single-family units were sold, on average, with a $5.06 \%$ transaction price premium when compared to otherwise identical buildings within a one-mile radius. The lower and upper $95 \%$ confidence intervals for the premium with robust standard errors are $0.0317(3.22 \%)$ and 0.0672 (6.95\%), respectively. Based on anecdotal evidence from local builders, EarthCraft reports an upfront cost premium of 0.5-3\%, suggesting that housebuilders' sales-time profit tends to be higher than normal when building certified units.

\subsection{Do green-certified houses cause positive market value spillover effects?}

The impact of the control variables in Model 2 is robust to the inclusion of new variables. The negative and statistically significant coefficient for Near EC, the binary variable that controls for pre-treatment price trends of units located within a quarter-mile of certified units, implies that the baseline transaction prices of the units are, on average, $2.28 \%$ lower than those of comparable units located outside the quarter-mile radius. This price difference indicates that there has been a systematic choice by developers in locating certified units in slightly less expensive areas, suggesting the $5.06 \%$ transaction price premium is not due to positive spatial externalities, thus, justifying the need for the use of the difference-in-difference specification. In Model 2, the positive and statistically significant difference-in-difference estimate indicates that, controlling for the 
baseline price differential of units located inside the one-quarter-mile radius and comparable units outside this walkability threshold, certified units cause market value spillovers on nearby, noncertified units. Following the construction of a new certified unit nearby, the average single-family unit transaction price of $\$ 331,844.20$ in the year 2019 would increase by $\$ 14,165.08$ (i.e., $4.27 \%$ ). We can expect the price increase to build up over time and at a decreasing rate, as increased competition from the supply of new housing units would reduce the pressure on local housing values. Also, we can expect the spillover effect to vary within different stages of development and depending on whether the new unit is a new structure on an existing plot of vacant land - which may reduce green space and increase congestion - or a redevelopment of an existing unit, which can improve neighborhood amenities, but the MLS dataset does not contain the data on preexisting conditions [49].

\subsection{Are green-certified houses connected with neighborhood change and gentrification?}

We first investigate the association between certified house accessibility and transaction price appreciation over time. Let us consider the hypothetical "high redevelopment potential zone" as the zone that includes units located within a one-mile radius of a certified unit like any other units in the sample but within the first quintile of certified unit accessibility as determined by the mean geodesic distance to all existing certified units in each year. Households living in this zone, which happens to overlap the Richmond City center, would have the highest potential for spatial interaction with the households of EarthCraft-certified units. In Model 3, the negative and statistically significant coefficients for the dependent variables Q2 to Q5 EC Accessibility, which determine year-specific quintiles of certified unit accessibility, imply that, on average, transaction prices of the units located in this zone, as determined by Q1, are $12.21 \%$ higher than those of identical units located elsewhere with the lowest level of certified unit accessibility. Now, we 
interact the level of accessibility with the sales year to indicate how much cumulative appreciation over time is associated with a non-certified unit being close to all the certified units. Table 4 reports a summary of the full two-way factorial model of accessibility quintiles and sales year, controlling for the structural, lot, and neighborhood characteristics of sales as well as the fixed effects of the sales city, year, and month. In Model 4, the positive and statistically significant coefficients for the interaction terms imply that accessibility to existing certified units has systematically affected unit price appreciations over time. Figure 3 compares cumulative appreciation rates for units located in the high redevelopment potential zone with those located in the other four zones. Independent sample t-tests show that in most years, the cumulative appreciation rate differences are statistically significant. 
Table 4 Summarized factorial model of sales year and certified unit accessibility quintiles

\begin{tabular}{|c|c|c|c|c|c|}
\hline & Model 4 & & & & \\
\hline Variable & Coef. & Robust Std. Err. & Variable & Coef. & Robust Std. Err. \\
\hline Q2 EC Accessibility $(1=$ yes $)$ & 0.0054 & 0.0106 & & & \\
\hline Q3 EC Accessibility (1 = yes) & 0.0127 & 0.0100 & & & \\
\hline Q4 EC Accessibility $(1=$ yes $)$ & 0.0009 & 0.0098 & & & \\
\hline Q5 EC Accessibility (1 = yes) & $0.0231 * *$ & 0.0103 & & & \\
\hline Q2 EC Accessibility 2007 & -0.0177 & 0.0159 & Q4 EC Accessibility 2007 & $0.0132 * * *$ & 0.0145 \\
\hline Q2 EC Accessibility 2008 & $0.0671 * * *$ & 0.0186 & Q4 EC Accessibility 2008 & 0.0168 & 0.0161 \\
\hline Q2 EC Accessibility 2009 & $-0.0622 * * *$ & 0.0189 & Q4 EC Accessibility 2009 & $0.0161 * * *$ & 0.0166 \\
\hline Q2 EC Accessibility 2010 & $-0.0648 * * *$ & 0.0190 & Q4 EC Accessibility 2010 & $0.0168 * * *$ & 0.0162 \\
\hline Q2 EC Accessibility 2011 & $-0.0947 * * *$ & 0.0201 & Q4 EC Accessibility 2011 & $0.0195^{* * *}$ & 0.0167 \\
\hline Q2 EC Accessibility 2012 & $-0.1383 * * *$ & 0.0186 & Q4 EC Accessibility 2012 & $0.0174 * * *$ & 0.0163 \\
\hline Q2 EC Accessibility 2013 & $-0.1211 * * *$ & 0.0162 & Q4 EC Accessibility 2013 & $0.0151 * * *$ & 0.0150 \\
\hline Q2 EC Accessibility 2014 & $-0.1612 * * *$ & 0.0168 & Q4 EC Accessibility 2014 & $0.0153^{* * *}$ & 0.0153 \\
\hline Q2 EC Accessibility 2015 & $-0.1586 * * *$ & 0.0161 & Q4 EC Accessibility 2015 & $0.0152 * * *$ & 0.0147 \\
\hline Q2 EC Accessibility 2016 & $-0.1425 * * *$ & 0.0163 & Q4 EC Accessibility 2016 & $0.0149 * * *$ & 0.0144 \\
\hline Q2 EC Accessibility 2017 & $-0.1314 * * *$ & 0.0162 & Q4 EC Accessibility 2017 & $0.0143^{* * *}$ & 0.0141 \\
\hline Q2 EC Accessibility 2018 & $-0.0983 * * *$ & 0.0170 & Q4 EC Accessibility 2018 & $0.0147 * * *$ & 0.0142 \\
\hline Q2 EC Accessibility 2019 & $-0.0624 * * *$ & 0.0167 & Q4 EC Accessibility 2019 & $0.0145^{* * *}$ & 0.0141 \\
\hline Q3 EC Accessibility 2007 & 0.0156 & 0.0139 & Q5 EC Accessibility 2007 & $0.0143 * * *$ & 0.0147 \\
\hline Q3 EC Accessibility 2008 & -0.0133 & 0.0172 & Q5 EC Accessibility 2008 & $0.0171 * *$ & 0.0163 \\
\hline Q3 EC Accessibility 2009 & $-0.0497 * * *$ & 0.0166 & Q5 EC Accessibility 2009 & $0.0170^{* * *}$ & 0.0167 \\
\hline Q3 EC Accessibility 2010 & $-0.0768 * * *$ & 0.0172 & Q5 EC Accessibility 2010 & $0.0176^{* * *}$ & 0.0163 \\
\hline Q3 EC Accessibility 2011 & $-0.0691 * * *$ & 0.0193 & Q5 EC Accessibility 2011 & $0.0192 * * *$ & 0.0167 \\
\hline Q3 EC Accessibility 2012 & $-0.1161 * * *$ & 0.0176 & Q5 EC Accessibility 2012 & $0.0177 * * *$ & 0.0164 \\
\hline Q3 EC Accessibility 2013 & $-0.1445 * * *$ & 0.0158 & Q5 EC Accessibility 2013 & $0.0156^{* * *}$ & 0.0151 \\
\hline Q3 EC Accessibility 2014 & $-0.1415 * * *$ & 0.0156 & Q5 EC Accessibility 2014 & $0.0157 * * *$ & 0.0153 \\
\hline Q3 EC Accessibility 2015 & $-0.1402 * * *$ & 0.0149 & Q5 EC Accessibility 2015 & $0.0151^{* * *}$ & 0.0147 \\
\hline Q3 EC Accessibility 2016 & $-0.1298 * * *$ & 0.0149 & Q5 EC Accessibility 2016 & $0.0151^{* * *}$ & 0.0145 \\
\hline Q3 EC Accessibility 2017 & $-0.1298 * * *$ & 0.0144 & Q5 EC Accessibility 2017 & $0.0148 * * *$ & 0.0142 \\
\hline Q3 EC Accessibility 2018 & $-0.1311 * * *$ & 0.0149 & Q5 EC Accessibility 2018 & $0.0153 * * *$ & 0.0143 \\
\hline Q3 EC Accessibility 2019 & $-0.1338 * * *$ & 0.0146 & Q5 EC Accessibility 2019 & $0.0150 * * *$ & 0.0142 \\
\hline Structure variables & Included & & & & \\
\hline Lot variables & Included & & & & \\
\hline Neighborhood variables & Included & & & & \\
\hline Sales city fixed effects & Included & & & & \\
\hline Sales year fixed effects & Included & & & & \\
\hline Sales month fixed effects & Included & & & & \\
\hline Constant & $4.3928 * * *$ & 0.1467 & & & \\
\hline Observations & 52,373 & & & & \\
\hline Adj R-squared & 0.8648 & & & & \\
\hline
\end{tabular}



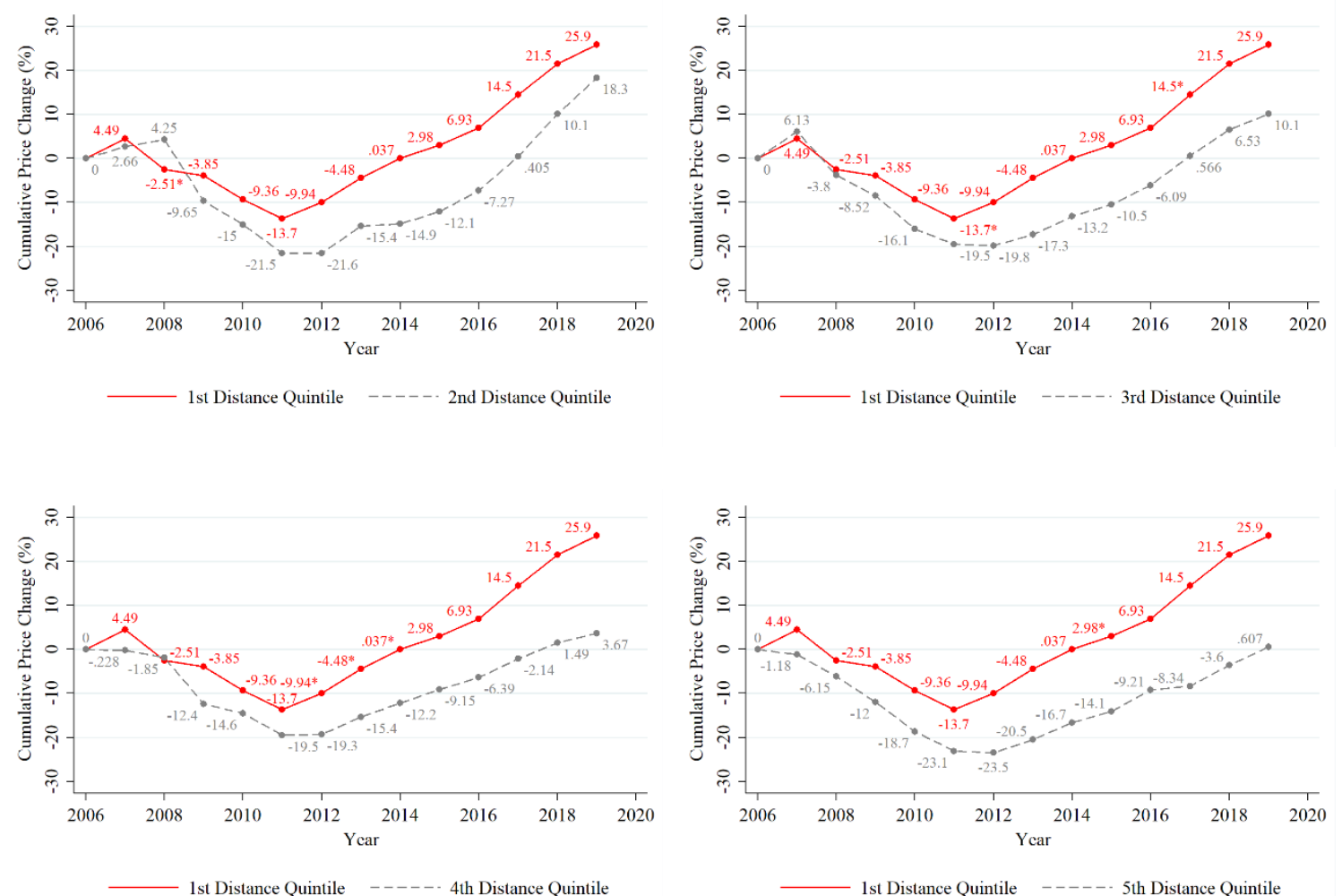

Figure 3 The effect of being close to green-certified units on cumulative home value appreciation is in most years statistically significant. Asterisks indicate statistically insignificant differences in cumulative appreciation.

In the year 2006, the median transaction prices for units in the first to the fifth accessibility quintiles were $\$ 200,000, \$ 195,000, \$ 232,000, \$ 277,000$, and $\$ 322,000$, respectively. Based on Model-4, the predicted average price appreciation from 2006-2019 for a unit located in the high redevelopment potential zone is $25.9 \%$. The predicted high redevelopment potential zone price appreciation premiums are $7.6 \%, 15.8 \%, 22.23 \%$, and $25.29 \%$ when compared to units in the second to the fifth accessibility quintiles, respectively. The median price unit in the first accessibility quintile (\$200,000 in 2006) achieved, on average, $\$ 51,800$ value in appreciation, whereas the appreciation for the median-priced unit in the fifth accessibility quintile $(\$ 322,000$ in 2006) was only $\$ 1,954$ in the same period. House value appreciations in the high redevelopment 
potential zone can raise tax revenues of the Richmond City and realize capital gains for property owners at the sales time, but owners and renters with limited disposable incomes will likely see increases in property taxes and rents. Following, Landis [6] we consider a Census block group as gentrifying if it is among one of the lowest four median household income deciles early on and is improved by two or more deciles at the end of the study period; we designate a Census block group as declining if it is among one of the highest four deciles in 2000 and is declined by two or more deciles in 2019; and we designate the remaining block groups as "stable", which implies these areas could be at the risk of decline or gentrification in different degrees. Since this approach may over-simplify the issue as there would need to be evidence of people being forced to leave these areas rather than only increases in income, we later examine more detailed changes in community characteristics. Figure 4 presents the location of units of high redevelopment potential (i.e., Q1 level of accessibility to certified units) and the location of gentrifying, stable, and declining block groups, indicating associations between certified unit accessibility and substantial upgrading in Richmond City core. Figure 5 presents single-family unit price change trends in Richmond City versus other areas in the submarket, indicating middle-class inmigration from suburbs to the city. The large price appreciation gap created in the 2010s has recently diminished. 


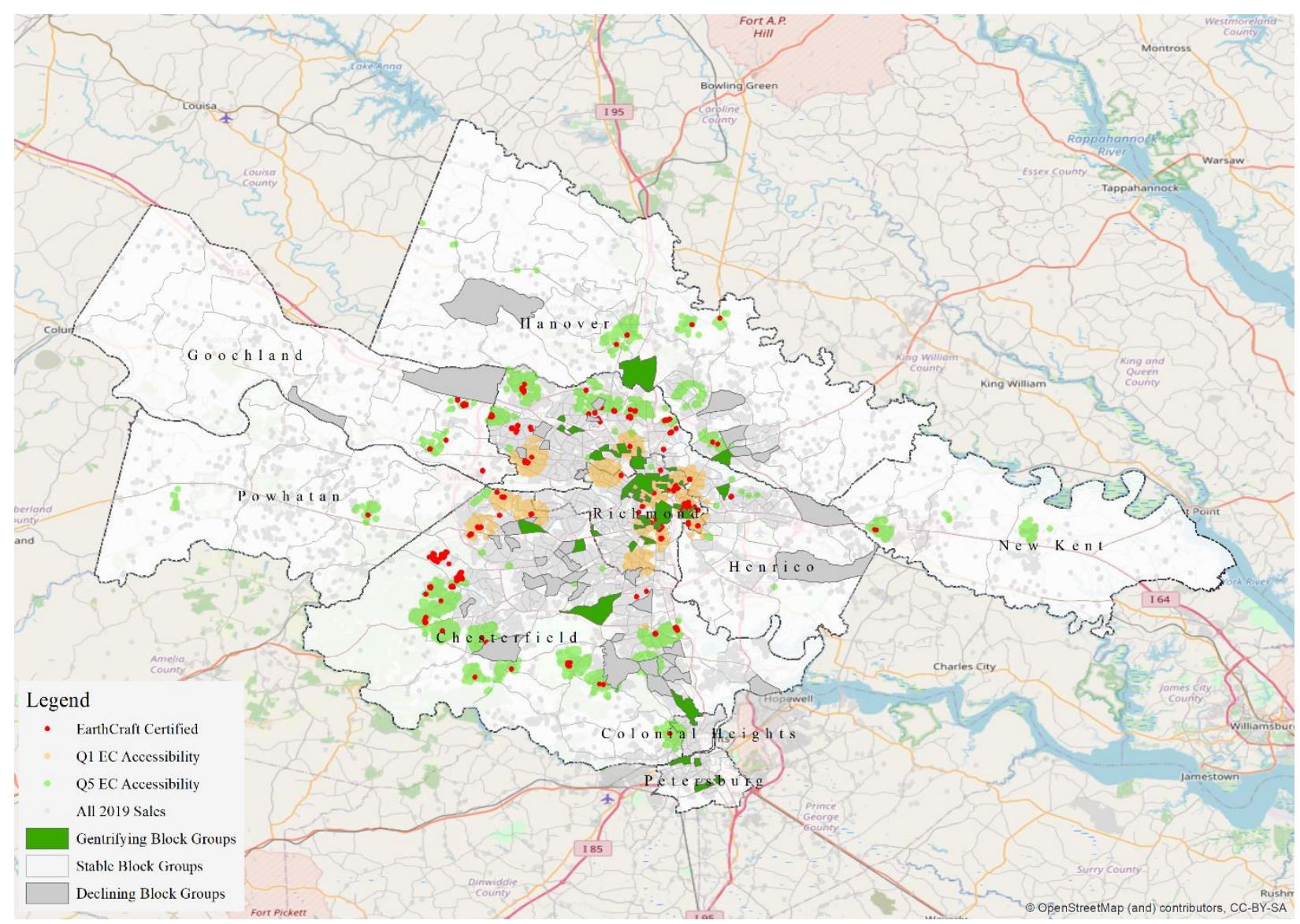

Figure 4 Gentrifying, stable, and declining block groups



Richmond City

Other Study Areas

Figure 5 Single-family unit price change trends in Richmond City versus other areas in the submarket 
To explore the connection between the construction of certified units and neighborhood change and gentrification in more detail, we identify Census tracts and block groups that are sites of certified units as two distinct treatment groups in two natural experiments. We approximate a propensity score matching, regressing the natural log of odds of the presence of certified units on the variables Age, Education, Income, Owner Costs, Population, Poverty, Renter Costs, Size, Vacancy, White, and the neighborhood centroid's distance to the Richmond City's central business district to identify the two control groups. The matching control group is those neighborhoods in which the propensity to site certified units is within the propensity score range of the treatment neighborhoods. Table 5 reports our selected socioeconomic variables, definitions, and descriptive statistics, as well as the resulting sample sizes. Table 6 reports the results of the pre-test, post-test, and difference-in-difference analyses, showing that the socioeconomic characteristics of the treatment and control groups are not statistically different at the outset within both tract level and block group level experiments. The tract-level experiment suggests that the new construction of certified units has not caused statistically significant effects on demographics, households, and housing characteristics during the last two decades. However, the block group level analysis shows that the new construction of certified units has stimulated population growth, housing development, and housing value increases, and the effects are statistically significant. Figure 6 includes selected variables from the block group level analysis with large or statistically significant mean differences before (the year 2000 data) and after (the year 2019 data) the construction of certified units in the treatment (red) and control (gray) groups. For instance, the difference between population means in both groups in 2000 is nearly zero, whereas the treatment group has gained significantly more population in two decades, resulting in $\$ 31,420$ additional value gain per unit by 2019 . 
Table 5 Variable definitions and pre-test and post-test descriptive statistics

\begin{tabular}{|c|c|c|c|c|c|c|c|c|c|}
\hline Variable & Operationalization & Treatm & nent & & & Contro & & & \\
\hline \multicolumn{10}{|l|}{ Tract-Level } \\
\hline Year & & 2000 & & 2019 & & 2000 & & 2019 & \\
\hline Observations & & 51 & & 51 & & 145 & & 145 & \\
\hline Demographics & & Mean & S.D. & Mean & S.D. & Mean & S.D. & Mean & S.D. \\
\hline Age & (\%) Population aged 25-39 & 22.3 & 5.8 & 21.4 & 7.5 & 22.5 & 6.3 & 21.6 & 8.5 \\
\hline Education & (\%) Population with a BA degree or higher & 29.8 & 19.3 & 38.4 & 19.1 & 28.2 & 18.3 & 33.2 & 19.2 \\
\hline Population & Total population (in 1,000 s) & 4.3 & 1.9 & 5.4 & 2.5 & 4.0 & 1.7 & 4.5 & 1.9 \\
\hline White race & (\%) White population & 61.7 & 35.2 & 59.0 & 27.4 & 63.4 & 34.3 & 57.2 & 28.0 \\
\hline \multicolumn{10}{|l|}{ Households } \\
\hline Income & Median household income (in $\$ 1,000$ s) & 51.7 & 23.8 & 76.5 & 33.8 & 48.2 & 23.0 & 70.0 & 35.7 \\
\hline Minority & (\%) Households who are Black, Hispanic, and Latino & 34.8 & 34.5 & 34.6 & 29.1 & 33.2 & 30.8 & 38.4 & 29.5 \\
\hline Minority owners & (\%) Owners who are Black, Hispanic, and Latino & 31.9 & 34.4 & 31.7 & 29.3 & 30.1 & 31.2 & 32.2 & 29.9 \\
\hline Minority renters & (\%) Renters who are Black, Hispanic, and Latino & 38.9 & 34.5 & 40.8 & 29.7 & 37.4 & 31.9 & 47.1 & 30.4 \\
\hline Owner costs & Median housing costs as a percentage of income & 19.4 & 2.3 & 19.0 & 3.6 & 19.2 & 2.4 & 19.0 & 3.4 \\
\hline Poverty & (\%) Households in poverty & 10.7 & 11.7 & 10.8 & 8.9 & 10.3 & 11.2 & 14.0 & 13.5 \\
\hline Renter costs & Median gross rent as a percentage of income & 25.2 & 5.6 & 30.3 & 7.2 & 24.9 & 5.4 & 31.1 & 7.2 \\
\hline Size & (\%) Small-sized (1-2 persons) households & 57.1 & 9.8 & 64.4 & 10.7 & 59.4 & 10.5 & 64.2 & 10.1 \\
\hline Tenure & (\%) Owner households & 70.3 & 20.7 & 66.4 & 21.5 & 66.7 & 24.2 & 62.4 & 25.3 \\
\hline \multicolumn{10}{|l|}{ Housing } \\
\hline Units & Total occupied housing units (in $1,000 \mathrm{~s}$ ) & 1.8 & 0.7 & 2.2 & 0.9 & 1.7 & 0.7 & 1.8 & 0.8 \\
\hline Vacancy & (\%) Vacant houses & 7.1 & 7.0 & 7.7 & 5.4 & 5.8 & 4.3 & 7.6 & 5.8 \\
\hline Value & Median owner-occupied house value $(\$ 1,000)$ & 126.7 & 61.1 & 266.3 & 119.1 & 116.6 & 65.4 & 235.2 & 127.7 \\
\hline EC transactions & & & & 8.5 & 11.2 & & & & \\
\hline \multicolumn{10}{|c|}{ Block Group-Level } \\
\hline Year & & 2000 & & 2019 & & 2000 & & 2019 & \\
\hline Observations & & 68 & & 68 & & 464 & & 464 & \\
\hline \multicolumn{10}{|l|}{ Demographics } \\
\hline Age & (\%) Population aged 25-39 & 21.9 & 6.6 & 21.3 & 9.7 & 22.6 & 7.3 & 21.3 & 9.6 \\
\hline Education & (\%) Population with a BA degree or higher & 29.6 & 20.2 & 16.4 & 11.1 & 28.5 & 19.4 & 14.0 & 10.7 \\
\hline Population & Total population (in $1,000 \mathrm{~s}$ ) & 1.5 & 0.9 & 2.3 & 1.6 & 1.5 & 0.8 & 1.7 & 0.9 \\
\hline White race & (\%) White population & 56.8 & 36.3 & 57.1 & 30.4 & 62.6 & 31.9 & 58.5 & 29.8 \\
\hline \multicolumn{10}{|l|}{ Households } \\
\hline Income & Median household income (in $\$ 1,000$ s) & 53.4 & 27.8 & 81.7 & 47.3 & 49.9 & 21.5 & 70.4 & 36.1 \\
\hline Minority & (\%) Households who are Black, Hispanic, and Latino & 38.3 & 36.8 & 37.1 & 31.5 & 32.1 & 31.9 & 37.0 & 30.6 \\
\hline Minority owners & (\%) Owners who are Black, Hispanic, and Latino & 35.7 & 36.6 & 33.5 & 32.3 & 29.5 & 31.7 & 31.8 & 30.6 \\
\hline Minority renters & (\%) Renters who are Black, Hispanic, and Latino & 39.9 & 38.4 & 43.0 & 35.6 & 34.9 & 34.3 & 43.1 & 34.8 \\
\hline Owner costs & Median housing costs as a percentage of income & 20.2 & 5.3 & 19.7 & 5.9 & 19.5 & 4.2 & 18.7 & 5.6 \\
\hline Poverty & (\%) Households in poverty & 11.6 & 13.5 & 11.0 & 10.9 & 9.8 & 11.7 & 11.7 & 13.2 \\
\hline Renter costs & Median gross rent as a percentage of income & 23.9 & 9.5 & 24.6 & 14.7 & 24.4 & 8.5 & 25.3 & 14.9 \\
\hline Size & (\%) Small-sized (1-2 persons) households & 56.6 & 11.0 & 62.9 & 13.6 & 59.2 & 11.6 & 64.1 & 14.0 \\
\hline Tenure & (\%) Owner households & 69.7 & 25.6 & 68.4 & 26.7 & 70.4 & 24.9 & 65.4 & 26.9 \\
\hline \multicolumn{10}{|l|}{ Housing } \\
\hline Units & Total occupied housing units (in $1,000 \mathrm{~s}$ ) & 0.6 & 0.3 & 0.9 & 0.5 & 0.6 & 0.3 & 0.7 & 0.4 \\
\hline Vacancy & (\%) Vacant units & 7.7 & 7.2 & 8.1 & 7.8 & 5.5 & 5.1 & 7.6 & 7.7 \\
\hline Value & Median owner-occupied unit value (in $\$ 1,000$ s) & 134.0 & 83.8 & 277.5 & 152.7 & 118.8 & 64.6 & 224.2 & 124.0 \\
\hline EC transactions & & & & 6.4 & 9.8 & & & & \\
\hline
\end{tabular}


Table 6 Difference-in-differences analyses results

\begin{tabular}{|c|c|c|c|c|c|c|c|c|c|c|}
\hline Analysis & \multicolumn{2}{|l|}{ Treatment } & \multicolumn{2}{|l|}{ Control } & \multicolumn{2}{|c|}{ Control-Treatment } & \multicolumn{2}{|c|}{ Control-Treatment } & \multicolumn{2}{|c|}{ Diff-in-Diff } \\
\hline \multicolumn{11}{|l|}{ Tract Level } \\
\hline Year & \multicolumn{2}{|l|}{$2019-2000$} & \multicolumn{2}{|l|}{$2019-2000$} & \multicolumn{2}{|l|}{2000} & \multicolumn{2}{|l|}{2019} & \multicolumn{2}{|l|}{ 2000-2019 } \\
\hline Demographics & Mean & S.E. & Mean & S.E. & Mean & S.E. & Mean & S.E. & Coef. & S.E. \\
\hline Age & -0.93 & 0.98 & $-0.90 *$ & 0.52 & 0.16 & 1.01 & 0.18 & 1.34 & -0.02 & 1.68 \\
\hline Education & $8.66^{* * *}$ & 1.27 & $5.00 * * *$ & 0.61 & -1.57 & 3.03 & $-5.23 *$ & 3.13 & 3.66 & 4.35 \\
\hline Population & $1.10^{* * *}$ & 0.29 & $0.50 * * *$ & 0.11 & -0.37 & 0.29 & $-0.97 * * *$ & 0.34 & 0.60 & 0.45 \\
\hline White race & -2.69 & 1.94 & $-6.17 * * *$ & 1.41 & 1.67 & 5.62 & -1.82 & 4.53 & 3.49 & 7.22 \\
\hline \multicolumn{11}{|l|}{ Households } \\
\hline Income & $24.81 * * *$ & 2.23 & $21.77 * * *$ & 1.36 & -3.48 & 3.78 & -6.53 & 5.74 & 3.04 & 6.87 \\
\hline Minority & -0.23 & 1.93 & $5.20 * * *$ & 1.05 & -1.58 & 5.18 & 3.85 & 4.79 & -5.43 & 7.05 \\
\hline Minority owners & -0.23 & 1.90 & $2.16^{* *}$ & 1.05 & -1.82 & 5.22 & 0.57 & 4.84 & -2.38 & 7.12 \\
\hline Minority renters & 1.93 & 2.45 & $9.68 * * *$ & 1.72 & -1.42 & 5.31 & 6.33 & 4.92 & -7.75 & 7.24 \\
\hline Owner costs & -0.48 & 0.55 & -0.14 & 0.26 & -0.28 & 0.39 & 0.02 & 0.56 & -0.30 & 0.68 \\
\hline Poverty & 0.02 & 0.98 & $3.67 * * *$ & 0.51 & -0.42 & 1.84 & 3.23 & 2.03 & -3.64 & 2.74 \\
\hline Renter costs & $5.02 * * *$ & 1.03 & $6.16^{* * *}$ & 0.69 & -0.30 & 0.89 & 0.80 & 1.18 & -1.10 & 1.47 \\
\hline Size & $7.37 * * *$ & 0.97 & $4.77 * * *$ & 0.64 & 2.35 & 1.68 & -0.26 & 1.67 & 2.60 & 2.37 \\
\hline Tenure & $-3.93 * * *$ & 1.28 & $-4.28 * * *$ & 0.69 & -3.62 & 3.80 & -3.97 & 3.97 & 0.35 & 5.49 \\
\hline \multicolumn{11}{|l|}{ Housing } \\
\hline Units & $0.43 * * *$ & 0.12 & $0.16^{* * *}$ & 0.04 & -0.13 & 0.11 & -0.40 & 0.13 & 0.27 & 0.18 \\
\hline Vacancy & 0.67 & 0.83 & $1.81 * * *$ & 0.33 & -1.30 & 0.84 & -0.17 & 0.93 & -1.14 & 1.25 \\
\hline Value & $139.56^{* * * *}$ & 9.14 & $118.17 * * *$ & 5.75 & -10.11 & 10.47 & $-31.12 * * *$ & 20.46 & 21.00 & 22.96 \\
\hline Observations & 51 & & 145 & & & & & & & \\
\hline \multicolumn{11}{|c|}{ Block Group Level } \\
\hline Year & \multicolumn{2}{|l|}{ 2019-2000 } & \multicolumn{2}{|l|}{ 2019-2000 } & \multicolumn{2}{|l|}{2000} & \multicolumn{2}{|l|}{2019} & \multicolumn{2}{|c|}{ 2000-2019 } \\
\hline Demographics & Mean & S.E. & Mean & S.E. & Mean & S.E. & Mean & S.E. & Coef. & S.E. \\
\hline Age & -0.56 & 1.02 & $-1.38 * * *$ & 0.38 & 0.68 & 0.93 & -0.14 & 1.26 & 0.68 & 1.55 \\
\hline Education & $-13.14 * * *$ & 1.63 & $-14.48 * * *$ & 0.56 & -1.09 & 2.53 & $-2.42 *$ & 1.39 & 1.29 & 2.89 \\
\hline Population & $0.76^{* * *}$ & 0.18 & $0.25^{* * *}$ & 0.04 & -0.02 & 0.10 & $-0.54 * * *$ & 0.13 & $0.51 * * *$ & 0.17 \\
\hline White race & 0.34 & 1.73 & $-4.24 * * *$ & 0.70 & 5.75 & 4.21 & 1.17 & 3.89 & 4.40 & 5.73 \\
\hline \multicolumn{11}{|l|}{ Households } \\
\hline Income & $28.33 * * *$ & 3.39 & $20.25 * * *$ & 1.08 & -3.54 & 2.90 & $-11.61 * *$ & 4.89 & 7.84 & 5.68 \\
\hline Minority & -1.16 & 1.78 & $4.85 * * *$ & 0.66 & -0.06 & 3.99 & -6.15 & 4.23 & -6.06 & 5.81 \\
\hline Minority owners & -2.26 & 1.96 & $2.51 * * *$ & 0.73 & -1.59 & 4.01 & -6.23 & 4.20 & -4.55 & 5.81 \\
\hline Minority renters & 2.67 & 3.59 & $7.28 * * *$ & 1.22 & 0.09 & 4.57 & -5.01 & 4.52 & -5.17 & 6.43 \\
\hline Owner costs & -0.56 & 0.83 & $-0.76^{* *}$ & 0.31 & -0.75 & 0.57 & -0.95 & 0.74 & 0.18 & 0.92 \\
\hline Poverty & -0.63 & 1.13 & $1.83^{* * *}$ & 0.38 & -1.79 & 1.55 & 0.68 & 1.67 & -2.51 & 2.28 \\
\hline Renter costs & 0.72 & 1.67 & 0.80 & 0.73 & 0.51 & 1.12 & 0.59 & 1.94 & -0.17 & 2.23 \\
\hline Size & $6.25 * * *$ & 1.18 & $4.89 * * *$ & 0.57 & 2.60 & 1.49 & $1.24 *$ & 1.85 & 1.32 & 2.34 \\
\hline Tenure & -1.32 & 1.21 & $-5.13 * * *$ & 0.60 & 0.65 & 3.24 & -3.16 & 3.50 & 3.67 & 4.76 \\
\hline \multicolumn{11}{|l|}{ Housing } \\
\hline Units & $0.27 * * *$ & 0.07 & $0.08^{* * *}$ & 0.01 & 0.01 & 0.04 & $-0.18 * * *$ & 0.05 & $0.19 * * *$ & 0.06 \\
\hline Vacancy & 0.40 & 0.98 & $2.20 * * *$ & 0.32 & -2.23 & 0.70 & $-0.44 * * *$ & 1.02 & -1.71 & 1.22 \\
\hline Value & $143.49 * * *$ & 9.95 & $104.70 * * *$ & 4.36 & $-15.18^{*}$ & 8.73 & -53.96 & 16.64 & $38.11 * * *$ & 18.76 \\
\hline Observations & 68 & & 467 & & & & & & & \\
\hline
\end{tabular}






M (C-T 2000): $-0.02, \mathrm{M}$ (C-T 2019): $-0.54^{* * *}$, DID: $0.51^{* * *}$

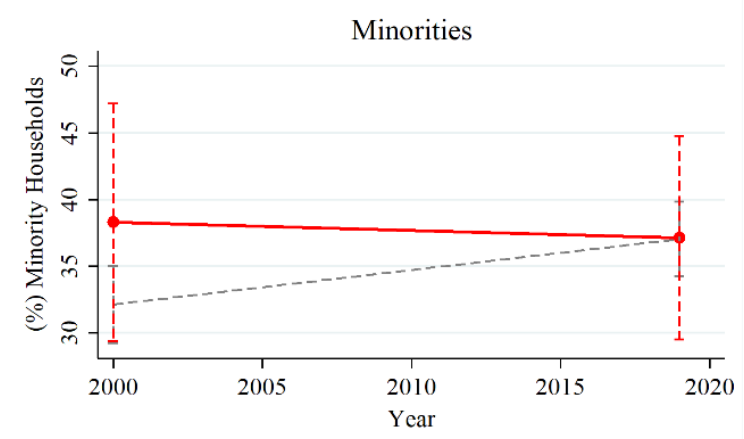

M (C-T 2000): -0.06, M (C-T 2019): -6.15, DID: -6.06



M (C-T 2000): 0.65, M (C-T 2019): -3.16, DID: 3.67

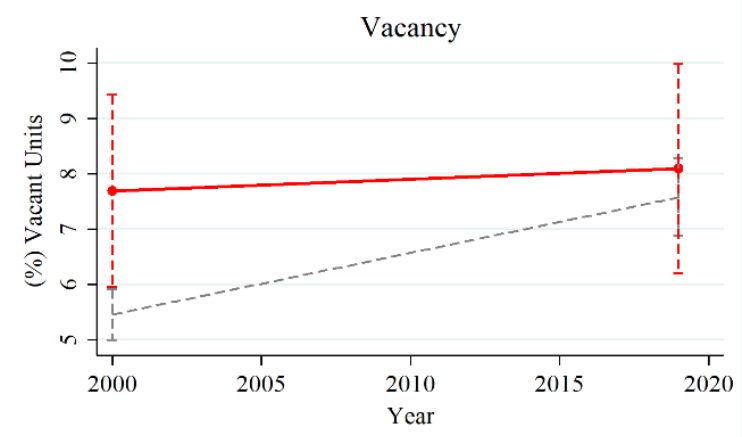

M (C-T 2000): -2.23, M (C-T 2019): -0.44***, DID: -1.71

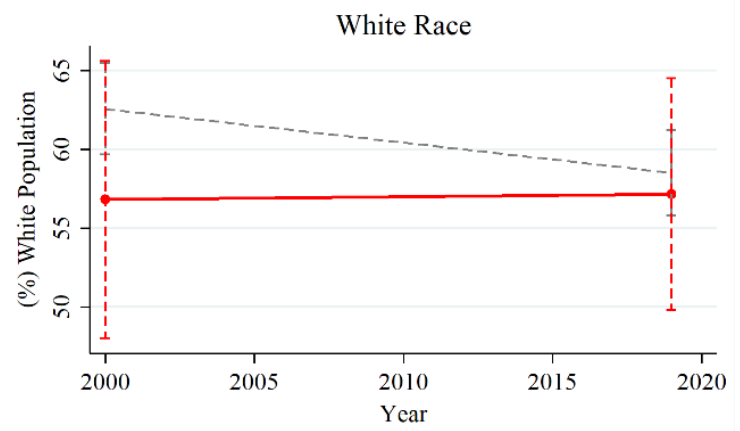

M (C-T 2000): 5.75, M (C-T 2019): 1.17, DID: 4.40

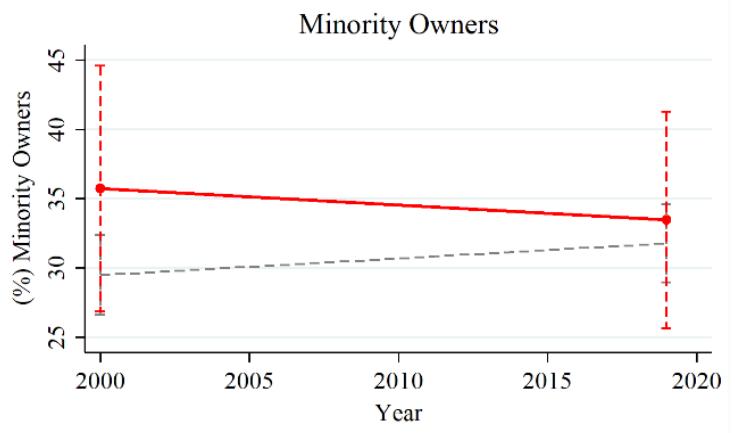

M (C-T 2000): -1.59, M (C-T 2019): -6.23, DID: -4.55

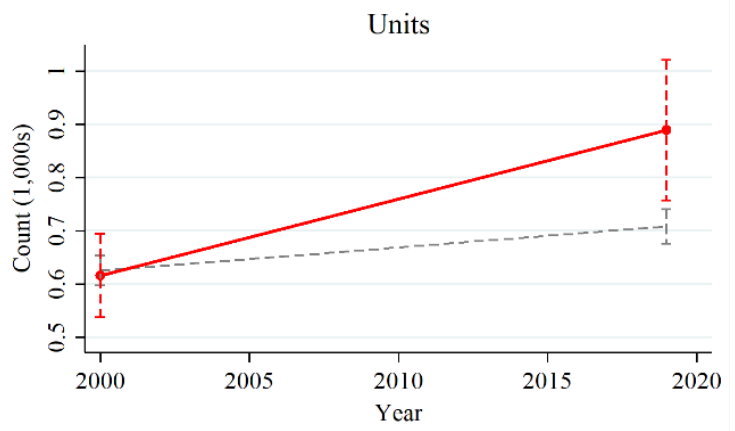

M (C-T 2000): 0.01, M (C-T 2019): -0.18***, DID: 0.19***

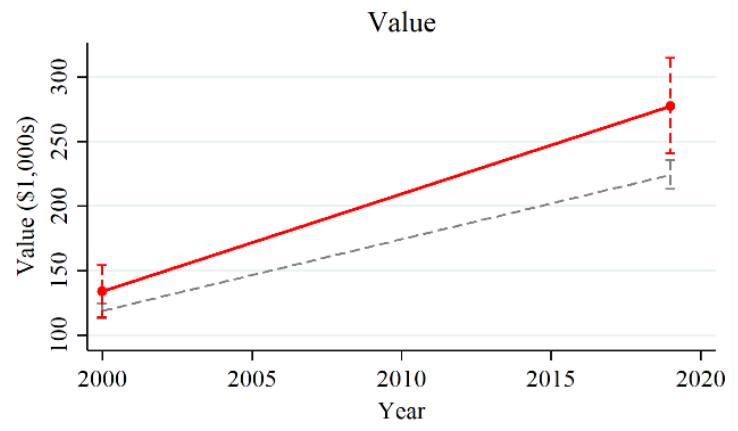

M (C-T 2000): -15.18*, M (C-T 2019): -53.96, DID: $38.11^{* * *}$ 
Figure 6 Selected Census block group level mean differences before (the year 2000) and after (the year 2019) the construction of green-certified units in treatment (red) and control (gray) areas. Asterisks indicate statistically significant differences in mean differences and bars represent upper and lower confidence interval values. The difference-in-difference estimate for Value is $\$ 31,420$ after adjusting for inflation.

\subsection{Has the influence of green certifications on house prices decreased over time?}

Using Equation (2) in a repeated pooled cross-sectional design for units sold in the three periods of 2005-2009, 2010-2014, 2015-2019, results suggest that the positive effect of green certification on prices increased in the mid-2010s, when transactions achieve, on average, $6.49 \%$ premium (Table 7). However, the analysis suggests that the positive effect of green certifications on prices reduced considerably from the year 2015 with a mean value of $3.37 \%$. Past research supports the mid-2010s as an inflection point in the value of green certifications from the perspective of professionals, as the technologies were becoming diffused in the market and increasingly standard [52].

Table 7 Repeated OLS regression analyses of single-family house prices based on the theory of the hedonic prices

\begin{tabular}{|c|c|c|c|c|c|c|}
\hline & \multicolumn{2}{|c|}{$2004<Y<2010$} & \multicolumn{2}{|c|}{$2009<Y<2015$} & \multicolumn{2}{|l|}{$2014<Y$} \\
\hline & Coef. & Std. Err. & Coef. & Std. Err. & Coef. & Std. Err. \\
\hline EarthCraft & 0.0040 & 0.0272 & $0.0629 * * *$ & 0.0121 & $0.0331 * *$ & 0.0156 \\
\hline Structure & Included & & Included & & Included & \\
\hline Location & Included & & Included & & Included & \\
\hline Neighborhood & Included & & Included & & Included & \\
\hline Sales city fixed effects & Included & & Included & & Included & \\
\hline Sales year fixed effects & Included & & Included & & Included & \\
\hline Sales month fixed effects & Included & & Included & & Included & \\
\hline Constant & $3.7903 * * *$ & 0.2154 & $3.7174 * * *$ & 0.2744 & $5.5323^{* * * * *}$ & 0.2002 \\
\hline Observations & 19,226 & & 15,839 & & 22,608 & \\
\hline Adj R-squared & 0.8951 & & 0.8655 & & 0.8476 & \\
\hline
\end{tabular}




\section{Discussion}

\subsection{Key results and comparison with previous research}

We find evidence to support the first hypothesis by showing that certified units have statistically significant price premiums. After becoming green certified, an average single-family unit in the sample with the transaction price of $\$ 331,844.20$ in the year 2019 would achieve, on average, a $5.06 \%$ (i.e., $\$ 16,791.32$ ) transaction premium. The new, green-certified units have a $19.87 \%$ price premium $(\$ 65,934.24)$ compared to existing non-certified units in a one-mile radius. The presence of favorable market conditions, supportive political regulations and incentives, and high-income clients would ensure builders recover the upfront costs through this transaction premium.

Second, we find convincing evidence to support the next hypothesis that certified units cause positive and statistically significant spillover effects. Following the construction of a new certified unit in the study period, the value of an average single-family unit in a walkable distance to the new, certified unit increases, on average, by $4.27 \%$. The baseline transaction prices of the units in walkable distance to certified units are, on average, $2.28 \%$ lower than those of comparable units located outside the quarter-mile radius, thus, supporting studies that argue investments in pro-environmental initiatives tend to occur in brownfields and urban areas where the difference between the actual and potential ground rent is high.

Third, the results reinforce the hypothesized connection between the construction of certified units and neighborhood change at the Census group level. The analysis indicates that the construction of certified units, based on several measures, stimulates population, new construction, and property value growth at the Census block group level, thus, accelerating 
neighborhood change and making the areas ripe for gentrification. We find large but not statistically significant changes in the selected socioeconomic indicators of gentrification before and after the construction of certified units. For instance, in Census block groups where certified units are located, there is an upward trajectory in the share of the White population and, consequently, a reduction in both household share and ownership rates for Blacks, Hispanics, and Latinos, suggesting that neighborhoods in the treatment group are at risk for gentrification. At the same time, the share of the White population in the control group has decreased and, thus, been replaced by non-Whites. Although there is an overall decrease in ownership and occupancy rates, the treatment group neighborhoods have more stable ownership and occupancy. The difference-in-difference analysis suggests that the construction of certified units has a more immediate effect on housing characteristics like the value and quantity of new developments than household characteristics like the class composition of households, e.g., increases in the White, prime-age, college-educated, middle- or high-income households, whose changes would achieve statistical significance in longer terms than studied here. A lack of statistically significant evidence of shifts in the key Census socioeconomic metrics could be due to different factors. The study period is likely too short, changes are too recent, or aggregate data cannot capture these trends well. Therefore, more studies should follow up and try to better measure this finding.

Lastly, we find that the effect of green home certification inflates in the mid-2010s but then shrinks back as we move toward the end of the decade. It is likely that, on the one hand, green building technologies become more diffused in the market and increasingly standard, thus, less expensive, and on the other hand, because of improvements in residential building codes and construction methods and the inclusion of green features in non-certified developments, 
homebuyers or builders may perceive smaller differences in operational benefits of certified units.

\subsection{Research and policy recommendations}

The choice of data, analysis unit, boundary, and timeframe impact inferences about neighborhood change and gentrification. The purpose of using area-level socioeconomic status data, which is often aggregated to protect the privacy of individuals, is to approximate individuallevel data, but the use of such proxies for individual socioeconomic status is a limitation as it can systematically underestimate changes in individuals' status [53]. The application of administrative units of analysis, e.g., Census-defined boundaries in the U.S., is often done out of convenience, but these boundaries are not always internally homogeneous for individuals' status [25].

The size of the geographical unit should reflect the magnitude of the expected effects without violating data reliability, but there seems to be no consensus on the geographical scale and timeframe in the definition of neighborhood change and gentrification. The smallest geographical unit for which socioeconomic data are available in Decennial Census is the Census block and in the American Community Survey, it is the Census block group. Many studies use the Census tract as the geographical unit based on which neighborhood change and gentrification should be defined and measured, but in the case of small environmental initiatives like green-certified units, such geographically small effects may not be detected at the tract level.

Nonetheless, quantitative methods can help overcome theoretical limitations by enabling policymakers to estimate the number of individuals who have been displaced or are at risk of displacement because of reinvestment in environmental burdens. In this case, the share of minority households among all households who live in Census block groups that house certified units has

\section{Page 38 of 44}


decreased, on average, by $6.06 \%$, and the share of owner households who are in minority has decreased, on average, by $4.55 \%$, both in difference-in-difference terms (Table 6).

This research highlights the need for greater policy attention to affordable housing needs in core urban areas, neighborhood diversity, and costs of gentrification. Pro-environmental reinvestments in city centers are likely to cause large-scale gentrification, thus, requiring planners to create a balance between the demands of environmental activists and the concerns of social justice advocates in crafting housing policies. Proposals to create this balance may include performing social effects assessments (e.g., vulnerability analysis), linking pro-environment development with affordable housing preservation, creating an even distribution of environmental amenities in the city to ensure equal benefits, employing mandatory inclusionary housing policies, exercising property tax growth limits, tax deferment programs, and property tax reductions for low-income households or affordable housing landlords [44,54]. This analysis supports past research by showing that the positive spillover effects of pro-environmental redevelopment projects quickly capitalize into housing prices in the area, thus, accelerating the growth in housing costs and neighborhood change. Once the risk of gentrification is recognized, planners should acknowledge that "development without displacement" requires early-stage diversity and affordability interventions as integral components of planning. Participatory planning and design processes, e.g., including the current community members in the process, can also ensure the community voice is integrated in new housing. Otherwise, significant increases in land values would make future community protection and improvement actions very expensive. Furthermore, as green certification programs increasingly look for added value, community-based scoring and activism is one opportunity. 


\section{Conclusion}

Middle- and higher-income residents are migrating from suburbs to the city to live in energyefficient units in mixed-use, dense, walkable, bikeable neighborhoods. Investments in environmental initiatives in brownfields and core urban areas, where the difference between the actual and potential ground rent is high, can replace low-rent units occupied by low-socioeconomic status residents with high-end real estate for higher-income, often white in-migrants. In the case of green-certified, single-family housing units, we find evidence of many of the conditions that make areas ripe for gentrification, e.g., by stimulating population growth, new construction, and property value increases. When a neighborhood is subject to gentrification, the cost-burdened, relocated, or displaced residents incur economic costs, social costs, and health and well-being costs, thus, requiring support from the host neighborhood and creating large negative externalities leading to welfare loss in the city. Since the net change in economic, environmental, and social benefits for the city of selective adoption of sustainability can be zero or even negative, planners should create a balance between the demands of environmental activists and the concerns of social justice advocates by crafting housing policies that protect social as well as environmental sustainability. One likely partner could be green certification programs themselves. Both need to fully understand the problems before they can affect change, though. Climate change is set to reshape future population distributions, triggering large-scale migrations away from affected areas and disproportionately escalating existing hardships faced by low-socioeconomic status populations [55-57]. Amid an unraveling climate crisis, a lack of consideration for affordable housing in urban reform, renewal, revitalization, and redevelopment plans endangers the health and wellbeing of the working class and low-income households who are essential to a functioning economy [27]. 


\section{References}

1. Zuo, J.; Zhao, Z.-Y. Green Building Research-Current Status and Future Agenda: A Review. Renew. Sustain. Energy Rev. 2014, 30, 271-281.

2. Hwang, J.; Lin, J. What Have We Learned About the Causes of Recent Gentrification? Cityscape 2016, 18, 9-26.

3. Hoyt, H. The Structure and Growth of Residential Neighborhoods in American Cities; US Government Printing Office: Washington, D.C., USA., 1939;

4. Davidson, M.; Lees, L. New-Build 'Gentrification'and London's Riverside Renaissance. Environ. Plan. A 2005, 37, 1165-1190.

5. Glass, R. London: Aspects of Change; MacGibbon \& Kee, 1964;

6. Landis, J.D. Tracking and Explaining Neighborhood Socioeconomic Change in U.S. Metropolitan Areas Between 1990 and 2010. Hous. Policy Debate 2016, 26, 2-52, doi:10.1080/10511482.2014.993677.

7. Checker, M. Wiped Out by the "Greenwave": Environmental Gentrification and the Paradoxical Politics of Urban Sustainability. City Soc. 2011, 23, 210-229, doi:10.1111/j.1548-744X.2011.01063.x.

8. Rice, J.L.; Cohen, D.A.; Long, J.; Jurjevich, J.R. Contradictions of the Climate-Friendly City: New Perspectives on Eco-Gentrification and Housing Justice. Int. J. Urban Reg. Res. 2020, 44, 145-165, doi:10.1111/1468-2427.12740.

9. Anderson, N.S.; Busà, A.; Brown, E.; Candipan, J.; Conn, P.; Cordeau, R.; DiFazio, W.; Farrell, S.; Gould, K.A.; Krase, J. The World in Brooklyn: Gentrification, Immigration, and Ethnic Politics in a Global City; Lexington Books, 2012;

10. Dong, H. Rail-Transit-Induced Gentrification and the Affordability Paradox of TOD. $J$. Transp. Geogr. 2017, 63, 1-10, doi:10.1016/j.jtrangeo.2017.07.001.

11. Gould, K.A.; Lewis, T.L. Green Gentrification: Urban Sustainability and the Struggle for Environmental Justice; Routledge, 2016;

12. Loughran, K. Parks for Profit: The High Line, Growth Machines, and the Uneven Development of Urban Public Spaces. City Community 2014, 13, 49-68, doi:10.1111/cico.12050.

13. Bowen, K.J.; Cradock-Henry, N.A.; Koch, F.; Patterson, J.; Häyhä, T.; Vogt, J.; Barbi, F. Implementing the "Sustainable Development Goals": Towards Addressing Three Key Governance Challenges - Collective Action, Trade-Offs, and Accountability. Curr. Opin. Environ. Sustain. 2017, 26-27, 90-96, doi:10.1016/j.cosust.2017.05.002.

14. Briassoulis, H. Policy Integration for Complex Environmental Problems: The Example of Mediterranean Desertification; Routledge, 2017;

15. Tosun, J.; Leininger, J. Governing the Interlinkages between the Sustainable Development Goals: Approaches to Attain Policy Integration. Glob. Chall. 2017, 1, 1700036, doi:10.1002/gch2.201700036.

16. Cejudo, G.M.; Michel, C.L. Addressing Fragmented Government Action: Coordination, Coherence, and Integration. Policy Sci. 2017, 50, 745-767, doi:10.1007/s11077-017-92815.

17. Persson, \AAsa; Runhaar, H. Conclusion: Drawing Lessons for Environmental Policy Integration and Prospects for Future Research. Env. Sci Policy 2018, 85, 141-145. 
18. Schmidt, N.M.; Fleig, A. Global Patterns of National Climate Policies: Analyzing 171 Country Portfolios on Climate Policy Integration. Environ. Sci. Policy 2018, 84, 177-185, doi:10.1016/j.envsci.2018.03.003.

19. Campbell, S. Green Cities, Growing Cities, Just Cities?: Urban Planning and the Contradictions of Sustainable Development. J. Am. Plann. Assoc. 1996, 62, 296-312.

20. Banzhaf, S.; Ma, L.; Timmins, C. Environmental Justice: The Economics of Race, Place, and Pollution. J. Econ. Perspect. 2019, 33, 185-208, doi:10.1257/jep.33.1.185.

21. Kronenberg, J.; Haase, A.; Łaszkiewicz, E.; Antal, A.; Baravikova, A.; Biernacka, M.; Dushkova, D.; Filčak, R.; Haase, D.; Ignatieva, M.; et al. Environmental Justice in the Context of Urban Green Space Availability, Accessibility, and Attractiveness in Postsocialist Cities. Cities 2020, 106, 102862, doi:10.1016/j.cities.2020.102862.

22. Di Gregorio, M.; Nurrochmat, D.R.; Paavola, J.; Sari, I.M.; Fatorelli, L.; Pramova, E.; Locatelli, B.; Brockhaus, M.; Kusumadewi, S.D. Climate Policy Integration in the Land Use Sector: Mitigation, Adaptation and Sustainable Development Linkages. Environ. Sci. Policy 2017, 67, 35-43, doi:10.1016/j.envsci.2016.11.004.

23. Runhaar, H. Tools for Integrating Environmental Objectives into Policy and Practice: What Works Where? Environ. Impact Assess. Rev. 2016, 59, 1-9, doi:10.1016/j.eiar.2016.03.003.

24. Anguelovski, I. From Toxic Sites to Parks as (Green) LULUs? New Challenges of Inequity, Privilege, Gentrification, and Exclusion for Urban Environmental Justice. J. Plan. Lit. 2016, 31, 23-36.

25. Kirk, D.S.; Laub, J.H. Neighborhood Change and Crime in the Modern Metropolis. Crime Justice 2010, 39, 441-502.

26. Sheppard, S. Why Is Gentrification a Problem?; Center for creative community development, 2012;

27. Rigolon, A.; Németh, J. "We're Not in the Business of Housing:" Environmental Gentrification and the Nonprofitization of Green Infrastructure Projects. Cities 2018, 81, 71-80, doi:10.1016/j.cities.2018.03.016.

28. Fuerst, F. Building Momentum: An Analysis of Investment Trends in LEED and Energy Star-Certified Properties. J. Retail Leis. Prop. 2009, 8, 285-297.

29. Fuerst, F.; Kontokosta, C.; McAllister, P. Determinants of Green Building Adoption. Environ. Plan. B Plan. Des. 2014, 41, 551-570, doi:10.1068/b120017p.

30. Rakha, T.; Moss, T.W.; Shin, D. A Decade Analysis of Residential LEED Buildings Market Share in the United States: Trends for Transitioning Sustainable Societies. Sustain. Cities Soc. 2018, 39, 568-577, doi:10.1016/j.scs.2018.02.040.

31. Kahn, M.E.; Kok, N. The Capitalization of Green Labels in the California Housing Market. Reg. Sci. Urban Econ. 2014, 47, 25-34.

32. U.S. Census Bureau Median Sales Price of Houses Sold for the United States Available online: https://fred.stlouisfed.org/series/MSPUS (accessed on 10 December 2020).

33. Walls, M.; Gerarden, T.; Palmer, K.; Bak, X.F. Is Energy Efficiency Capitalized into Home Prices? Evidence from Three US Cities. J. Environ. Econ. Manag. 2017, 82, 104-124.

34. Dippold, T.; Mutl, J.; Zietz, J. Opting for a Green Certificate: The Impact of Local Attitudes and Economic Conditions. J. Real Estate Res. 2014, 36, 435-473.

35. Copiello, S. Building Energy Efficiency: A Research Branch Made of Paradoxes. Renew. Sustain. Energy Rev. 2017, 69, 1064-1076, doi:10.1016/j.rser.2016.09.094. 
36. While, A.; Jonas, A.E.; Gibbs, D. The Environment and the Entrepreneurial City: Searching for the Urban 'Sustainability Fix' in Manchester and Leeds. Int. J. Urban Reg. Res. 2004, 28, 549-569.

37. Bunce, S. Developing Sustainability: Sustainability Policy and Gentrification on Toronto's Waterfront. Local Environ. 2009, 14, 651-667.

38. Goodling, E.; Green, J.; McClintock, N. Uneven Development of the Sustainable City: Shifting Capital in Portland, Oregon. Urban Geogr. 2015, 36, 504-527.

39. Freeman, L. Displacement or Succession? Residential Mobility in Gentrifying Neighborhoods. Urban Aff. Rev. 2005, 40, 463-491.

40. Urban Displacement Project Urban Displacement Project Available online: https://www.urbandisplacement.org/san-francisco/gentrification-and-displacement (accessed on 17 December 2020).

41. Ilic, L.; Sawada, M.; Zarzelli, A. Deep Mapping Gentrification in a Large Canadian City Using Deep Learning and Google Street View. PLOS ONE 2019, 14, e0212814, doi:10.1371/journal.pone.0212814.

42. Mujahid, M.S.; Sohn, E.K.; Izenberg, J.; Gao, X.; Tulier, M.E.; Lee, M.M.; Yen, I.H. Gentrification and Displacement in the San Francisco Bay Area: A Comparison of Measurement Approaches. Int. J. Environ. Res. Public. Health 2019, 16, doi:10.3390/ijerph16122246.

43. Barton, M. An Exploration of the Importance of the Strategy Used to Identify Gentrification. Urban Stud. 2016, 53, 92-111.

44. Immergluck, D.; Balan, T. Sustainable for Whom? Green Urban Development, Environmental Gentrification, and the Atlanta Beltline. Urban Geogr. 2018, 39, 546-562, doi:10.1080/02723638.2017.1360041.

45. Faul, F.; Erdfelder, E.; Buchner, A.; Lang, A.-G. Statistical Power Analyses Using G*Power 3.1: Tests for Correlation and Regression Analyses. Behav. Res. Methods 2009, 41, 1149-1160, doi:10.3758/BRM.41.4.1149.

46. Rosen, S. Hedonic Prices and Implicit Markets: Product Differentiation in Pure Competition. J. Polit. Econ. 1974, 82, 34-55.

47. Can, A. The Measurement of Neighborhood Dynamics in Urban House Prices. Econ. Geogr. 1990, 66, 254-272.

48. Gelman, A.; Hill, J. Data Analysis Using Regression and Multilevel/Hierarchical Models; Cambridge university press, 2006;

49. Ooi, J.T.L.; Le, T.T.T. The Spillover Effects of Infill Developments on Local Housing Prices. Reg. Sci. Urban Econ. 2013, 43, 850-861, doi:10.1016/j.regsciurbeco.2013.08.002.

50. Vincenty, T. Direct and Inverse Solutions of Geodesics on the Ellipsoid with Application of Nested Equations. Surv. Rev. 1975, 23, 88-93.

51. Gujarati, D.N. Basic Econometrics; Tata McGraw-Hill Education, 2009;

52. Tucker, J.R.; Pearce, A.R.; Bruce, R.D.; McCoy, A.P.; Mills, T.H. The Perceived Value of Green Professional Credentials to Credential Holders in the US Building Design and Construction Community. Constr. Manag. Econ. 2012, 30, 963-979.

53. Moss, J.L.; Johnson, N.J.; Yu, M.; Altekruse, S.F.; Cronin, K.A. Comparisons of Individual- and Area-Level Socioeconomic Status as Proxies for Individual-Level Measures: Evidence from the Mortality Disparities in American Communities Study. Popul. Health Metr. 2021, 19, 1, doi:10.1186/s12963-020-00244-x. 
54. Haase, D.; Kabisch, S.; Haase, A.; Andersson, E.; Banzhaf, E.; Baró, F.; Brenck, M.; Fischer, L.K.; Frantzeskaki, N.; Kabisch, N.; et al. Greening Cities - To Be Socially Inclusive? About the Alleged Paradox of Society and Ecology in Cities. Habitat Int. 2017, 64, 41-48, doi:10.1016/j.habitatint.2017.04.005.

55. Curran, W.; Hamilton, T. Just Green Enough: Contesting Environmental Gentrification in Greenpoint, Brooklyn. Local Environ. 2012, 17, 1027-1042.

56. Hauer, M.E. Migration Induced by Sea-Level Rise Could Reshape the US Population Landscape. Nat. Clim. Change 2017, 7, 321-325, doi:10.1038/nclimate3271.

57. Kulp, S.A.; Strauss, B.H. New Elevation Data Triple Estimates of Global Vulnerability to Sea-Level Rise and Coastal Flooding. Nat. Commun. 2019, 10, 4844, doi:10.1038/s41467019-12808-z. 